\title{
Algunas consideraciones sobre el receso en el Código Civil Peruano: A PROPÓSITO DEL ARTÍCULO 1786
}

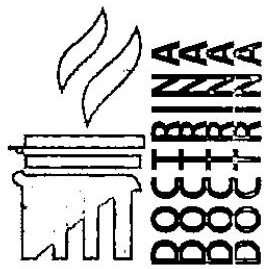

\section{Luciano Barchi Velaochaga}

Abogado por la Universidad de Lima. Profesor de Derecho Civil Patrimonial en la Universidad de Lima.

Magíster en Derecho con mención en Derecho Civil y candidato a Doctor por la Pontificia Universidad Católica del Perú. Miembro del Consejo Consultivo de la Revista ADVOCATUS.

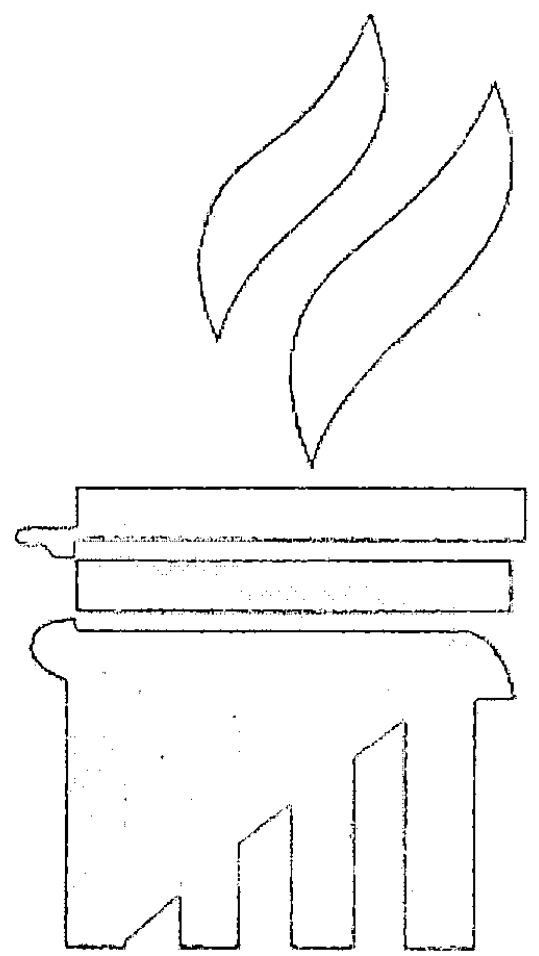

SUMARI0:

I. La facultad de receso.

II. Disolución y modificación del víncolo contractual:

1. Disolución y modificación del vínculo contractual por acuerdo de las partes;

2. Disolución del vínculo contractual por decisión unilateral de una de las partes.

III. En cuanto a la necesidad de entregar arras para conceder la facultad de recesar (retractarse).

IV. Respecto a que solo seria posible conceder la facultad de receso (retractación) en los contrarios preparatorios.

V. Las arras de retractación en el contrato de opción.

VI. Las arras de retractación en el compromiso de contratar.

VII. Las arras confirmatorias como contraprestación por el receso de autotutela.

VIII. El Pacto de retroventa en la compraventa.

IX. La naturaleza del receso.

$X$. La función del receso.

XI. Los efectos del receso.

XII. El contrato de obra como modalidad del contrato de prestación de servicios:

1. El tipo contractual;

2. El contrato de prestación de servicios;

3. El contrato de obra y el contrato de locación de servicios.

XIII. El receso legal ad nutum en el contrato de obra.

XIV. La indemnización en caso de receso del contrato de obra. 
A la memoria de Luis Velaochaga Velaochaga

\section{LA FACULTAD DE RECESO}

Como regla general cualquier modificación contractual requiere el acuerdo de las partes contratantes, en tal sentido, no es posible la modificación unilateral por alguna de las partes sin el consentimiento de la otra. Este principio encuentra consagración legislativa en el artícuto 1361 del Código Civil, el cual establece que "Ios contratos son obligatorios en cuanto se haya expresado en ellos".

Del artículo citado fluye la idea de "vínculo contractual", es decir, de la sujeción de las partes a los efectos del contrato.' El sentido del vínculo contractual se descompone en dos significa$\operatorname{dos}^{2}$ :

a) La resistencia del contrato al arrepentimiento de una de las partes: el vínculo contractual no se disuelve por voluntad unilateral de una de las partes la cual no desea continuar vinculada (imposibilidad de liberación unilateral o principio de la irrevocabilidad contractual); $y$,

b) La inmodificabilidad de la regulación contractual por decisión unilateral de una de las partes contractuales (imposibilidad de modificación unilateral o principio de vinculación y obligatoriedad). Giuffrè, Milano, 2002, p. 498.
Como bien reconoce Roppo, los principios señalados no son absolutos $y$, por tanto, admiten excepciones; es decir, los vínculos contractuales no son homogéneos y tienen una escala de intensidad variable. ${ }^{3}$ En tal sentido, debe afirmarse que el vínculo contractual no puede ser disuelto ni modificado unilateraimente por una de las partes, salvo acuerdo de las partes o por causas admitidas por la ley. ${ }^{4}$

\section{DISOLUCIÓN Y MODIFICACIÓN DEL VÍN- CULO CONTRACTUAL}

\section{Disolución y modificación del vínculo contractual por acuerdo de las partes}

El mutuo disenso es el contrato en virtud del cual las partes dejan sin efecto un precedente contrato entre ellas, liberándose del vínculo contractual. ${ }^{5}$ Teniendo en cuenta el carácter contractual del mutuo disenso la doctrina reconoce que ello no constituye una derogación al principio enunciado en el artículo 1361 del Código Civil. En este sentido Ambrosoli afirma: "En realidad el mutuo disenso (o contrario consenso) no es una derogación al principio de la fuerza de ley, sino es simplemente la aplicación de la regla de autonomía negocial, que legitima a las partes a celebrar contratos que tengan por objeto la resolución de precedentes relaciones contractuales". Del mismo modo las partes pueden, de común acuerdo, modificar un contrato celebrado previamente por ellas.

1 Temporalmente puede no darse la coincidencia entre vínculo y efectos, en tal sentido puede subsistir el vínculo aún si el contrato no produce todos sus efectos, como ocurre, por ejemplo, en el contrato sujeto a condición suspensiva.

2 ROPPO, Vincenzo, // Contratto. En: Trattato di Diritto Privato, Giuffrè, Milano, 2001, p. 533 y ss.

3 ROPPO, Vincenzo, //Contratto. En: Op. Cit., p. 535. En el mismo sentido DIENER, María Cristina, /Contratto in Generale,

4 La ley admite que en presencia de determinadas «causas» el vínculo contractual pueda disolverse o modificarse en sus contenidos por iniciativa de una de las partes; así por ejemplo, la resolución del contrato por incumplimiento.

5 El artículo 1313 del Código Civil señala que por el mutuo disenso las partes que han celebrado un acto jurídico acuerdan "dejarlo sin efecto". Cárdenas Quirós considera más adecuado señalar que por el mutuo disenso, las partes acuerdan "extinguir una relación obligatoria" (CÁRDENAS QUIRÓS, Carlos, Hacia la reforma del Libor VI del Código Civil. En:Thémis, Revista de Derecho, No. 30, Edición de Aniversario, p. 148). No compartimos la posición de Cárdenas Quirós pues en nuestra opinión no debe limitarse los efectos del contrato a la relación obligatoria. Un contrato con función translativa de la propiedad de bienes inmuebles genera de manera inmediata, conforme al artículo 949 del Código Civil, un efecto real y el mutuo disenso también deja sin efecto la transferencia de la titularidad de la propiedad.

6 AMBROSOLI, Matteo, La sopravvenienza contrattuale, Giuffrè, Milano, 2002, nota (11), p. 7. 
En síntesis, si el común acuerdo de las partes puede crear el vínculo contractual, también puede extinguirlo (contrato extintivo) o modificarlo (contrato modificativo).?

\section{Disolución del vínculo contractual por decisión unilateral de una de las partes}

El receso es el acto unilateral en virtud del cual una parte del contrato dispone dejarlo sin efecto. El receso es, en algunas legislaciones, una de las causas admitidas por la ley para la disolución del vínculo contractual por iniciativa de una sola de las partes.

El receso es materia de un derecho potestativo atribuido por la ley (receso legal) o por una cláusula del contrato (receso convencional), a ambas partes, o bien, a solo una de ellas. A la otra parte le corresponde una situación de sujeción, es decir, que solo le queda tolerar el ejercicio del receso, no se requiere su aceptación. En tal sentido el titular del derecho potestativo de receso tiene la facultad de elegir entre ejecutar el contrato o no ejecutarlo.

Los recesos legales son previstos por la disciplina de diversos contratos y tienen una lógica o función distinta entre ellos que permiten su agrupación en varias categorías: recesos de liberación, recesos de autotutela y recesos de arrepentimiento. $^{8}$

El derecho de receso puede ser ejercitado libremente (ad nutum $)^{9}$ o bien subordinado a la subsistencia de una justa causa. En el caso del receso ad nutum la parte en cuyo favor es atribuido el derecho de receso, puede ejercerlo en cualquier momento y sin necesidad de justificar el receso. El receso por justa causa, en cambio, solo se dará si se presentan deter- minadas circunstancias justificativas previstas específicamente por la ley o cuando esta remita a la apreciación del juez si el hecho alegado constituye justa causa.

Así, por ejemplo, el artículo 1769 del Código Civil prevé el receso de arrepentimiento por justa causa a favor del locador en el contrato de locación de servicios:

"El locador puede poner fin a la prestación de servicios por justo motivo, antes del vencimien to del plazo estipulado, siempre que no cause perjuicio al comitente.

Tiene derecho al reembolso de los gastos efectuados y a la retribución de los servicios prestados".

El artículo 1786 del Código Civil, al cual nos referiremos más adelante, prevé el receso de arrepentimiento ad nutum a favor del comitente en el contrato de obra.

El receso inmotivado o ad nutum es regulado en algunos Códigos Civiles. Este es el caso, por ejemplo, del Código Civil italiano. El artículo 1373 de dicho Código establece que:"Sia una de las partes le es atribuida la facultad de recesar del contrato, tal facultad puede ser ejercitada mientras que el contrato no haya tenido un principio de ejecución". Y más adelante, refiriéndose a los contratos de duración donde comúnmente se presenta esta facultad, dice: "En los contratos de ejecución continuada'o periódica, tal facultad puede ser ejercitada también sucesivamente, pero el receso no tiene efecto para las prestaciones ya ejecutadas o en curso de ejecución (...)".

Nuestro Código Civil admite casos de receso inmotivado (ad nutum) en los artículos 1365, 1736

7 Así, el artículo 1351 del Código Civil señala que el contrato es el acuerdo de dos o más partes para crear, regular, modificar o extinguir una relación jurídica patrimonial.

8 En este sentido ROPPO, Vincenzo, // Contratto. En: Trattato di Diritto Privato, Op. Cit., p. 550. SACCO, Rodolfo y DE NOVA, Giorgio, // Contratto, Tomo secondo, UTET, Torino, 1996, p. 694.

9 La expresión ad nutum es análoga a la expresión ad libitum y se utiliza para caracterizar una decisión que depende exclusivamente del arbitrio de una de las partes. 
y 1808 . Asimismo, a propósito de las arras de retractación (artículo 1480). No obstante, nuestro Código Civil no emplea el término receso. El lenguaje no es homogéneo, se habla de denuncia, desistimiento unilateral, resolución unilateral o de retractación (en las arras de retractación), pero se alude con dichas expresiones al mismo fenómeno: la extinción o terminación de la relación contractual ya constituida, como consecuencia de la voluntad de una de las partes. Una cuestión distinta es si, fuera de esos casos, es válido conforme al Código Civil, el acuerdo en virtud del cual se le atribuye a una de las partes la facultad de retirarse de un contrato ya concluido. En otras palabras, si es válido el receso convencional ad nutum.

De conformidad con el artículo 1354 del Código $\mathrm{Civil}^{10}$ parece no haber objeción respecto a la validez del receso convencional ad nutum. Asimismo, debe tenerse en cuenta que el receso convencional no es otra cosa que una condición resolutoria meramente potestativa" y que tal condición es válida de acuerdo al Código Civil, puesto que el artículo 172 solo considera nulo el acto jurídico cuyos efectos están subordinados a "condición suspensiva que depende de la exclusiva voluntad del deudor".

Sirena al respecto señala:

"Desde el punto de vista conceptual el derecho de receso corresponde perfectamente a la condición resolutoria potestativa, con la cual se identifica si ha sido voluntariamente previsto por las partes contratantes. Con mayor precisión, en caso que el receso voluntario sea incontrovertible, la cláusula que lo prevé se califica como condición resolutoria meramente potestativa, en cambio en caso que sea discrecional, es decir subordinado a determinados presupuestos de hecho (aún si elásticos, como la justa causa o el justificado motivo), se califica como condición resolutoria simple".12

No resulta entonces comprensible la razón por la cual el legislador peruano consideró en el artículo 1480 del Código Civil, que la entrega de arras de retractación "solo es válida en los contratos preparatorios".

El artículo 1480 del Código Civil establece:

"La entrega de las arras de retractación sóloes válida en los contratos preparatorios y concede a las partes el derecho de retractarse de ellas" (el subrayado es nuestro).

De acuerdo con el artículo citado la entrega de las arras es una suerte de "contraprestación" por la concesión del derecho a recesar (retractarse de acuerdo con el Código (ivil), pero solo se podría "comprar" el derecho de recesar (retractarse) tratándose de un contrato preparatorio. En otras palabras, parecería que en la legislación peruana el receso (retractación) solo es posible: si se paga una contraprestación (arras) y si se incluye en los contratos preparatorios. Esto no es exacto.

\section{EN CUANTO A LA NECESIDAD DE ENTRE- GAR ARRAS PARA CONCEDER LA FACUL- TAD DE RECESAR (RETRACTARSE)}

La doctrina unánimemente reconoce que el receso puede ser oneroso o gratuito. ${ }^{13}$ En este sentido Nuccia Parodi señala: "El receso puede

10 "Las partes pueden determinar libremente el contenido del contrato, siempre que no sea contrario a norma legal de carácter imperativo".

11 BIANCA, Massimo, Diritto Civile. 3 // Contratto, Giuffrè, Milano, 1998, p. 521. DIENER, Maria Cristina, Ob. Cit., p. 424. Roppo, encuentra una diferencia entre el receso y la condición resolutiva meramente potestativa y es que en el Codice Civile la condición tiene efecto retroactivo mientras el receso no. (ROPPO, Vincenzo, // Contratto. En: Op. Cit., pp. 618-619). No obstante recordemos que en el Código Civil la condición no tiene efecto retroactivo (articulo 177). Ver también SACCO, Rodolfo y DE NOVA, Giorgio, Op. Cit., p. 153.

12 SIRENA, Pietro, Effettie Vincolo. En: Trattato del Contratto, Diretto da Vincenzo Roppo, Tomo III, Giuffrè, Milano, 2006, p. 115.

13 En este sentido RAVERA, Enrico, // Recesso, Giuffrè, Milano, 2004, p. 209. También ver: ROPPO, Vincenzo, // Contratto. En: Op. Cit., p. 584. 
ser atribuido sin alguna contraprestación a cargo del recedente, o bien puede ser previsto el pago de una suma de dinero o de una prestación diversa".14 Así, no es indispensable la entrega de arras para otorgar la facultad de receso.

En la legislación italiana se admite la posibilidad de otorgar la facultad de receso a cambio de una contraprestación (receso oneroso) o sin ella (receso gratuito). Cuando se prevé la contraprestación, esta puede ser pagada al momento de la celebración del contrato y recibe el nombre de "arras penitenciales" 15 o puede ser prevista en caso de ejercer, y solo si se ejerce, el derecho potestativo de recesar, en cuyo caso se habla de "multa penitencial".16

En nuestro ordenamiento jurídico las "arras de retractación"17, en principio, se entregan a la celebración del contrato preparatorio y concede a las partes el derecho de recesar (retractarse) dicho contrato. En este caso estamos frente a un precio por la atribución del derecho potestativo (precio del receso), de tal manera que la entrega de las arras se produce con independencia de si se recesa o no. Esto supone que el "pacto de arras" tiene carácter real, en el sentido que se perfecciona con la entrega de las arras ${ }^{18}$, lo cual contradice lo dispuesto en el artículo 1352 del Código Civil. ${ }^{19}$
De acuerdo con lo previsto en el artículo 1481 del Código Civil, si recesa (retracta) la parte que entrega las arras, las pierde en provecho de quien las recibió. Si recesa (retracta) quien recibió las arras ${ }^{20}$, al momento de hacerlo, devuelve las recibidas y entrega una cantidad igual. Es decir, a quien recibió las arras se le atribuye una carga para ejercer la facultad de recesar "devolverlas dobladas" de tal manera que solo si las devuelve se produce el receso. La carga es una conducta que el sujeto debe necesariamente realizar para satisfacer su propio interés. La falta de realización de la carga impedirá obtener la ventaja prevista. La parte contraria no puede reclamar su ejecución.21

También es posible que se otorgue a una de las partes la facultad de recesar imponiéndosele como carga para su ejercicio el pago de una "contraprestación". En este caso la entrega de las arras solo deberá realizarse en la medida que el titular del derecho potestativo decida ejercer el receso.

\section{RESPECTO A QUE SOLO SERÍA POSIBLE CONCEDER LA FACULTAD DE RECESO (RETRACTACIÓN) EN LOS CONTRATOS PREPARATORIOS}

La Exposición de Motivos del artículo 1480 del Código Civil señala que el propósito de la restric-

14 PARODI, Nuccia, L'uscita progammata del contratto, Giuffrè, Milano, 2005, p. 49.

15 El artículo 1386 del Codice Civile se refiere a la "caparra penitenziale".

16 Último párrafo del artículo 1373 del Código Civil italiano: "En caso de haber sido estipulada una contraprestación por el receso, este tiene efecto cuando la prestación es ejecutada".

17 Las arras pueden consistir en una suma de dinero o en una cantidad de cosas fungibles. En caso se entreguen bienes determinados se entendería como "prenda" (ver BIANCA, Massimo, Diritto Civile. 5 La responsabilità, Giuffrè, Milano, 1994, p. 366).

18 La doctrina en general reconoce el carácter real de las arras (ver al respecto ALFONSO RODRIGUEZ, María Elvira, Las arras en la contratación, Bosch Editor, Barcelona, 1995, p. 222. En contra, DE LA PUENTE Y LAVALLE, Manuel, El Contrato General, Tomo III, Primera reimpresión, Palestra, Lima, 2003, p. 371.

19 "Los contratos se perfeccionan por el consentimiento de las partes, excepto aquellos que, además, deben observar la forma señalada por la ley bajo sanción de nulidad".

20 Conforme al artículo 1482 del Código Civil quien recibe las arras puede renunciar al derecho de retractación (receso).

21 Ver CABANILLAS SÁNCHEZ, Antonio, Las cargas en el Derecho Civily en el Mercantil, Montecorvo, Madrid, 1988. También ver MESSINEO, Francesco, Manual de Derecho Civil y Comercial, Tomo II, Ediciones Jurídicas Europa-América, Buenos Aires, 1979, p. 84 y ss. 
ción es "fortalecer la contratación", desalentando "los medios que faciliten el arrepentimiento de los contratantes".22

De acuerdo con Arias Schreiber: “(...) este precepto en su primera parte no tiene antecedentes legislativos, pero responde a la filosofía del Código, orientada al cumplimiento de los contratos y al desaliento de los medios que faciliten el arrepentimiento de los contratantes. Es por esto que la retractación solo es posible en el caso de los contratos preparatorios, pues en ellos todavia no se ha concretado la relación contractual final. En otras palabras, el propósito de esta restricción no es otro que fortalecer la contratación".23

Manuel De la Puente y Lavalle se preguntaba si era conveniente que el Derecho concediera a las partes contratantes el derecho de retractarse. El ilustre jurista peruano respondía diciendo:

"Pienso que no. Si alguien, al momento de celebrar un contrato, no desea cumplirlo sino en determinadas circunstancias, tiene a su disposición los recursos de supeditarlo a ocurrencia de una condición suspensiva o a la llegada de un plazo de igual clase, con lo cuallo privan temporalmente de eficacia. Puede, es más, celebrar un contrato simplemente preparatorio, que le permita reflexionar sobre la conveniencia de celebrar en el futuro un contrato definitivo e inamovible. Siendo así las cosas, resulta, si no atentatorio, al menos incongruente con un sistema semejante al conceder a las partes que han contratado definitivamente la posibilidad de "comprar» el derecho de arrepentirse". ${ }^{24}$
Si bien no compartimos lo señalado por De la Puente respecto a la supuesta incongruencia del receso convencional respecto a un sistema juridico orientado el cumplimiento contractual, es preciso advertir que más adelante, el jurista reconocia que si se admite la retractación para toda clase de contratos, pues con ello "no se está atentando contra los principios del orden público ni de las buenas costumbres y que, por el contrario, se está respetando el principio de la autonomia privada (...)".25 Con lo cual queda claro que para De la Puente y Lavalle el acuerdo en virtud del cual se otorga a una de las partes la facultad de recesar cualquier contrato, y no solo los contratos preparatorios, es válido.

En la práctica comercial es frecuente la inclusión de recesos convencionales en los "contratos de duración", siendo un caso frecuente el de los contratos de distribución. Al respecto Cándido Paz-Ares señala: "La experiencia enseñaque en la práctica la totalidad de los contratos de franquicia y concesión (...) contienen cláusulas de terminación ad nutum, en cuya virtud pueden ser denunciados en cualquier momento si han sido celebrados por tiempo indeterminado o no renovados cuando llegan a su término de vencimiento, si se han concertado por tiempo determinado. El significado de tales cláusulas es manifiesto. Lo que pretenden es garantizar la libertad de salida de las partes mediante la atribución a cada una de ellas de la facultad unilateral de poner término a la relación sin necesidad de indemnizar los daños que experimente la contraria ni de satisfacerle ninguna otra clase de compensación".26

22 ARIAS SCHREIBER PEZET, Max. Con la colaboración de CÁRDENAS QUIRÓS, Carlos y ARIAS SCHREIBER PEZET, Ángela, Código Civil. Exposición de Motivos y Comentarios, Tomo VI, Compiladora: REVOREDO DE MUR, Delia, Okura Editores, Lima, 1985, p. 156.

23 ARIAS SCHREIBER PEZET, Max, Con la colaboración de CÁRDENAS QUIRÓs, Carlos, ARIAS SCHREIBER MONTERO, Ángela y MARTíNEZ COCO, Elvira, Exégesis. Código Civil Peruano de 1984, Tomo I, Segunda Edición, Studium, Lima, 1987, p. 310.

DE LA PUENTE Y LAVALLE, Manuel, El Contrato General, Tomo III, Op. Cit., p. 378.

25 LOC. Cit.

26 PAZ-ARES, Cándido, La terminación de los contratos de distribución. En: ADVOCATUS, No. 8, p. 31. 
Pero el hecho de pretender, sin éxito, limitar el receso a los contratos preparatorios no solo desconoce la utilidad práctica del receso en la contratación moderna sino que resulta siendo, en algunos casos, absurda.

Nuestro Código Civil regula dos contratos preparatorio ${ }^{27}$ : el contrato de opción y el compromiso de contratar. Veamos el tema de las arras de retractación respecto a cada uno de ellos.

\section{LAS ARRAS DE RETRACTACIÓN EN EL CONTRATO DE OPCIÓN}

De acuerdo con el artículo 1419 del Código Civil:

"Por el contrato de opción, una de las partes queda vinculada a su declaración de celebrar en el futuro un contrato definitivo y la otra tiene el derecho exclusivo de celebrarlo o no".

Como señala Bianca: "La opción es el contrato que atribuye a una parte (optante) el derecho de constituir la relación contractual final mediante una propia declaración de voluntad".28

El contrato de opción no es constitutivo de una relación obligatoria. ${ }^{29}$ Veamos. La relación jurídica se estructura como una relación bipolar, donde se interrelacionan dos situaciones jurídicas, las cuales tienen como titular a, por lo menos, un sujeto de derecho. En este sentido, es una relación intersubjetiva.
Las situaciones juridicas son las posiciones que ocupan los sujetos de derecho tuteladas por el ordenamiento jurídico en cuanto expresiones de un interés merecedor de tutela.

Las situaciones jurídicas en cuanto polos de la relación son necesariamente términos heterogéneos, así encontramos ${ }^{30}$ :

a) Situaciones deventaja (o activas).- Las situaciones jurídicas de ventaja (o situaciones activas) son aquellas que se traducen en la atribución de un poder (por ejemplo, de exigir un determinado comportamiento de otro sujetoly se individualizan en el derecho subjetivo y en la relativas facultades, en el derecho potestativo, en la potestad, en la expectativa, en el legítimo interés y en los intereses difusos.

b) Situaciones de desventaja (o pasivas).- Las situaciones jurídicas de desventaja (o situaciones pasivas) son aquellas que atribuyen al sujeto un deber de comportamiento y se califican a través del deber, la obligación y la sujeción. ${ }^{31}$

En la relación obligatoria se interrelacionan dos situaciones jurídicas: una situación de ventaja: el crédito y una situación de desventaja: la obligación (o deuda); en tal sentido, el deudor (titular de la obligación) debe realizar una conducta (prestación) para satisfacer el interés del acreedor (titular del crédito) y este tiene el derecho de exigir la realización de esa conducta.

27 Sin embargo pueden reconocerse otras relaciones jurídicas preparatorias así, por ejemplo, la oferta irrevocable, el contrato normativo, las declaraciones de intención. Ver al respecto: / rapporti giuridici preparatori. A Cura di REALMONTE, Francesco, Giuffrè, Milano, 1996.

28 BIANCA, Massimo, Diritto Civile. 3 //Contratto, Op. Cit., p. 267.

29 En este sentido no es exacto que, conforme al artículo 1402 del Código Civil, el objeto del contrato consista en crear (cuando no regular, modificar o extinguir) obligaciones. En el contrato de opción no ocurre ello.

30 Rusciello distingue las situaciones jurídicas en "activas" $y$ "pasivas", siendo las primeras atributivas de una posición de ventaja y las segundas de desventaja (RUSCELLO, Francesco, Istituzioni di Diritto Privato, Volume Primo: Le nozioni generali. I soggetti, Seconda edizione, Giuffrè, Milano, 2005, p. 47).

31 Del deber, la obligación y la sujeción se distingue la carga que se da "cuando a un sujeto le es atribuido un poder, pero el ejercicio de tal poder está condicionado a un cumplimiento (que, sin embargo, siendo previsto en interés del mismo sujeto, no es obligatorio y por tanto no prevé sanciones para la hipótesis que no sea actuado" (TORRENTE, Andrea y SCHLESINGER, Pietro, Manuale di Diritto Privato, Diciottesima Edizione, Giuffrè, Milano, 2007, p. 83). 
El contrato de opción no genera una relación obligatoria sino una relación jurídica que tiene como situación de ventaja un derecho potestativo y como situación de desventaja una de sujeción..$^{32}$ Como señalan Caringella y De Marzo: "(...) en los derechos potestativos el titular está premunido del poder de actuar unilateralmentey modificar la esfera juridica del sujeto pasivo que, de su parte, no debe hacer nada para consentir que el titular del derecho consiga su interés, y no puede hacer nada para impedir que lo consiga. Este se encuentra, en efecto, en una situación de sujeción" ${ }^{\prime \prime 3}$ En efecto, el concedente de la opción no debe realizar ninguna conducta para satisfacer el interés del optante, este tiene la potestad de modificar la esfera juridica del concedente a través de su sola declaración de voluntad (del ejercicio de la opción). ${ }^{34}$

Siendo el optante titular de un derecho potestativo, no tiene sentido que "compre"la facultad de recesar el contrato de opción, puesto que le bastará renunciar al derecho del que es titular (renuncia de la opción) ${ }^{35} \mathrm{O}$, simplemente, no ejercerlo dejando vencer el plazo de vigencia de la opción para que se produzca su caducidad. En tal sentido, parece más lógico que sea el concedente quien compre la facultad de receso que le permita, eventualmente, liberarse de la situación de sujeción de la que es titular. Pero esto último parece poco probable que ocurra en la práctica puesto que la opción satisface el interés de poder evaluar y decidir sobre el negocio sin el temor de una inminente revocación. ${ }^{36} \mathrm{En}$ otras palabras lo que se busca con el contrato de opción es mantener fija e irrevocable, temporalmente, la propuesta referida al contrato definitivo.

Debe quedar claro que la entrega de arras de retractación permite recesar el contrato preparatorio. El hecho que, por ejemplo, el optante no ejerza la opción y, por tanto no se celebre el contrato definitivo, no supone receso o retractación.

Por otro lado, debe distinguirse las arras de retractación de la "prima" o el "precio" de la opción. En efecto, la opción puede ser onerosa o gratuita. ${ }^{37}$ Es onerosa cuando a cambio que le sea concedida la opción el optante deba pagar una contraprestación, la cual se conoce como "premio", "prima" o "precio" de la opción. Al respecto Talma Charles señala: "la opción es onerosa cuando el optante, a cambio del poder que se le ha concedido, debe hacer el sacrificio de pagar una prima o precio".38

32 Ver entre otros ROPPO, Vincenzo, / Contratto. En: Ob. Cit., p. 163. BIANCA, Massimo, Diritto Civile. 3 /l Contratto. Op. Cit., p. 271. SCIARRONE ALIBRANDI, Antonella, L'opzione. En: / rapproti giuridici preparatori. A cura di REALMONTE, Francesco, Giuffrè, Milano, 1996, p. 87 y ss. RUSCELLO, Francesco, Op. Cit., p. 54. De la Puente y Lavalle parece inferir que sí se genera una relación obligatoria (DE LA PUENTE Y LAVALLE, Manuel, El Contrato General, Tomo III, Op. Cit., p. 235).

33 CARINGELLA, Francesco y DE MARZO, Giuseppe, Manuale di Diritto Civile, Volume II, Le Obligazioni, Giuffrè, Milano, 2007, p. 21.

34 La opción puede ser también bilateral o reciproca, que sería el caso del pacto de call y put en la compraventa de acciones.

35 Se trata de una renuncia abdicativa. Respecto a la renuncia a los derechos ver CANO MARTÍNEZ DE VELASCO, J.I., La renuncia a los derechos, Bosch, Barcelona, 1986. Respecto a la renuncia de la opción ver TALMA CHARLES, Javier, EI contrato de opción, Bosch, Barcelona, 1996, p. 261.

36 ROPPO, Vincenzo, //Contratto. En: Op. Cit., p. 160.

37 Para un sector de la doctrina italiana la opción es siempre onerosa. La opción gratuita no es opción sino una simple propuesta irrevocable en este sentido SACCO, Rodolfo y DE NOVA, Giorgio, Op. Cit., p. 310. Sciarroni sostiene que se trata de una tesis minoritaria (Ver al respecto SCIARRONE ALIBRANDI, Antonella, Lopzione. En: Op. Cit., p. 69 y ss.), también ver sobre este tema ROPPO, Vincenzo, // Contratto. En: Op. Cit., p. 161. Para De la Puente y Lavalle "(...) el contrato de opción es naturalmente de prestación unilateral, también es naturalmente gratuito" (DE LA PUENTE Y LAVALLE, Manuel, El Contrato General, Tomo II, Op. Cit., p. 232).

38 TALMA CHARLES, Javier, Op. Cit., pp. 45-46. 
Para Roppo la "prima" es una obligación a cargo del optante..$^{39}$ En nuestra opinión, la naturaleza jurídica de la "prima" dependerá del acuerdo de las partes. En algunos casos el otorgamiento de la opción queda sujeto a la condición del pago de la "prima". En este caso se habla de "condición de cumplimiento" cuya particularidad, como señala Petrelli, "está dada por el hecho que el evento deducido como condición se identifica con el comportamiento de uno de los contratantes, que constituye a su vez, cumplimiento de una de las prestaciones del sinalagma contractual".40 No obstante, debe tenerse en cuenta que la doctrina y la jurisprudencia discuten sobre la posibilidad de deducir como condición la ejecución de una prestación. ${ }^{41}$

Por otro lado, cuando se le concede al optante la facultad de prorrogar la vigencia de la opción ("opción de prórroga de la opción") por determinados periodos debiendo pagar una "prima" por cada periodo que decida prorrogar, entonces es evidente la naturaleza de carga de la "prima". En este caso si el optante quiere mantener vigente la opción debe pagar la "prima", la no observancia de la carga (no pago de la "prima") determina la caducidad de la opción y, en ningún caso, quien otorgó la opción puede pretender su pago.

Si se entregan arras de retractación en un contrato de opción y no se ejerce la opción entonces no se produce la celebración del contrato definitivo (lo que implica, además, el no ejercicio de la facultad de receso), entonces, la parte que recibió las arras no está obligada a restituirlas, puesto que se le entregaron las arras por otorgarle a la otra el derecho de receso (retractación), independientemente si se ejercita o no. En cambio, de acuerdo con al artículo 1483 del Código Civil, si se ejerce la opción, lo que supone la celebración del contrato definitivo y por consiguiente, el no ejercicio de la facultad de receso (retractación), quien recibió las arras "las devolverá de inmediato o las imputará sobre su crédito, según la naturaleza de la prestación". Es decir, se le da la misma solución que en el caso de las arras confirmatorias en el artículo 1477 del Código Civil. Esta solución, a nuestro juicio, desnaturaliza las "arras de retractación" puesto que como hemos visto estas constituyen la contraprestación por conferir la facultad de receso (retractación) con independencia a su ejercicio, mientras que las arras confirmatorias no son otra cosa que un "pago a cuenta".

La opción puede presentarse como un negocio autónomo o puede estar contenida en el interior de un contexto contractual más complejo, como ocurre, por ejemplo, en el contrato de leasing o en el call y put de una compraventa de acciones. ${ }^{42}$ En este último caso, de acuerdo con la intención de nuestro legislador, la entrega de arras de retractación solo permitiría el receso del pacto de opción pero no del contrato en el cual dicho pacto está contenido.

\section{LAS ARRAS DE RETRACTACIÓN EN EL COMPROMISO DE CONTRATAR}

\section{De acuerdo con el artículo 1414 del Código} Civil:

"Por el compromiso de contratar las partes se obligan a celebrar en el futuro un contrato definitivo".

39 ROPPO, Vincenzo, // Contratto. En: Op. Cit., p. 163.

40 PETRELLI, Gaetano, La condizione «elemento esenziales del negozio giuridico. Teoria generales e profili applicativi, Giuffrè, Milano, 200, p. 436.

41 Ver al respecto LENZI, Raffaele, Condizione, autonomia privata e funzione di autotutela. L'adempimento dedotto in condizione, Giuffrè, Milano, 1996, p. 5 y ss.

42 Se vende, por ejemplo, el $40 \%$ de las acciones y las partes prevén una opción de compra por otro $20 \%$ (Call) a favor del comprador. Se prevé también que el comprador puede salir de la operación (receso) y, en tal caso, el vendedor deberá readquirir el $40 \%$ a un precio determinado (Put). Al respecto Nuccia Parodi señala: "Se puede conseguir los mismos efectos de un receso o de una resolución programada del contrato, utilizando opciones de compra (call) o de venta (put) o contratos preliminares" (PARODI, Nuccia, Op. Cit., p. 229). 
Como sintetiza Roppo: "El contrato preliminar es el contrato que obliga a las partes a concluir en el futuro un determinado contrato (contrato definitivo)".43 Quizá la definición de Bianca resulta más descriptiva cuando señala: "El contrato preliminar es el contrato mediante el cual una o ambas partes se obligan a la estipulación de un sucesivo contrato, llamado definitivo". ${ }^{44}$

En efecto, como se desprende de la definición de Bianca, el compromiso de contratar puede ser unilateral o bilateral. Es unilateral cuando solo una de las partes es la que se encuentra obligada, dentro de un plazo establecido, a celebrar en el futuro un contrato definitivo y la otra parte el derecho a exigirlo. ${ }^{45}$ Es bilateral cuando ambas partes se encuentran obligadas a celebrar en el futuro un contrato definitivo y ambas partes tienen el derecho de exigírselo a la otra.

Como puede apreciarse el compromiso de contratar si es creador de relaciones obligatorias. Sacco y De Nova sostienen que el compromiso de contratar no solo obliga a prestar el consentimiento para la conclusión del contrato definitivo sino que obliga a concluirlo, es decir a hacer todo aquello que es necesario y suficiente para que el contrato definitivo produzca sus efectos. ${ }^{46}$

Un caso particular parece ser el del denominado "Contrato de Opción Minera" que el artículo 165 de la Ley General de Minería ${ }^{47}$ define de la siguiente manera:

"Por el contrato de opción, el titular de una concesión se obliga, incondicional e irrevoca- blemente, a celebrar en el futuro un contrato definitivo, siempre que el opcionista ejercite su derecho de exigir la conclusión de este contrato, dentro del plazo estipulado".

Del artículo citado se desprende que el llamado "Contrato de Opción Minera" no se identifica con el "Contrato de Opción" regulado en el Código Civil, sino que, en realidad, parece ser un compromiso de contratar unilateral. Como advierte Roppo una diferencia entre la opción y el compromiso de contratar unilateral "es que la posición del promitente en el preliminar unilateral es de obligación, mientras aquella del optante es de sujeción (...".48

En efecto, conforme al artículo 165 de la Ley General de Minería en virtud del "Contrato de Opción Minera" se genera una relación obligatoria en virtud de la cual el titular de una concesión minera se obliga a celebrar en el futuro un contrato definitivo siempre que y solo si, la otra parte (el "opcionista") le exige la celebración del contrato dentro del plazo estipulado. Esto no quiere decir que, de conformidad con el principio de autonomía de voluntad, no sea posible celebrar un contrato de opción de transferencia de concesiones mineras conforme al Código Civil. Esto es importante puesto que, conforme al artículo 165 de la Ley General de Minería, el "Contrato de Opción Minera" (compromiso de contratar unilateral) "se celebrará por un plazo no mayor de cinco años, contados a partir de su suscripción". En cambio, si se celebra un contrato de opción en los términos del Código Civil, conforme al artículo 1416, no existe un plazo máximo.

43 ROPPO, Vincenzo, // Contratto. En: Op. Cit., p. 651. La legisiación italiana no habla de "compromiso de contratar" sino de "contrato preliminar".

44 BIANCA, Massimo, Diritto Civile. 3 // Contratto, Ob. Cit., p. 185. Ver también PALADINI, Mauro, Preliminare unilaterale, opzione, opzione di preliminare bilaterale. En: /l Contratto Preliminare, Giuffrè, Milano, 1992, p. 345.

45 En caso de incumplimiento de la obligación de contratar se recurre al remedio de la ejecución coactiva en forma específica (artículo 1418 del Código Civil).

46 SACCO, Rodolfo y DE NOVA, Giorgio, Op. Cit., pp. 272-273.

47 Texto Único Ordenado de la Ley General de Minería aprobado por el Decreto Supremo No. 014-1992-EM.

48 ROPPO, Vincenzo, //Contratto. En: Ob. Cit., p. 658. En el mismo sentido, BIANCA, Massimo, Diritto Civile. 3 // Contratto, Op. Cit., p. 201. 
Volviendo con nuestro tema, parece razonable que quien queda obligado a contratar en el compromiso de contratar unilateral, o ambas si el compromiso de contratar es bilateral, puedan tener interés en comprar la facultad de receso que les permita, eventualmente, liberarse de su obligación de contratar.

En el caso del compromiso de contratar unilateral quien tiene el derecho a que se celebre el contrato definitivo también puede dejar transcurrir el plazo de vigencia del compromiso para que se produzca la extinción de la relación obligatoria, pero no podría renunciar al derecho del que es titular. Esto último en la medida que, estando frente a una relación obligatoria, no cabe renuncia, entendida como un acto unilateral del titular del derecho, sino que, conforme al artículo 1295 del Código Civil, se requiere la condonación que supone un acuerdo entre el deudor y el acreedor.

\section{LAS ARRAS CONFIRMATORIAS COMO CONTRAPRESTACIÓN POR EL RECESO DE AUTOTUTELA}

En la práctica se suele suscribir un documento donde consta la entrega de arras confirmatorias y se le denomina: "contrato de arras". Normalmente este documento contiene propiamente un contrato de compraventa y las llamadas "arras confirmatorias" no son otra cosa que un "pago a cuenta". Esto desnaturaliza la función de las "arras confirmatorias" como seña que permite probar la conclusión de un contrato. Como afirma Alfonso Rodríguez tradicionalmente las arras confirmatorias han cumplido una finalidad probatoria o testimonial. ${ }^{49}$

Si hay un documento que sirve de prueba de la celebración de un contrato no tiene sentido hablar de arras confirmatorias con función probatoria sino simplemente de un "pago a cuenta". No obstante debe tenerse en consideración que no todos los pagos a cuenta deben considerarse como arras salvo que las partes le hayan atribuido tal función..$^{50}$

Pero las "arras confirmatorias" tiene otras funciones: la de contraprestación por el receso de autotutela y la de determinación anticipada del daño..$^{51}$

Cumplen una función de autotutela puesto que concede a ambas partes la facultad de recesar en caso que la otra parte inejecute la prestación a su cargo. Se trata de un poder que permite a la parte no incumpliente "dejar sin efecto" el contrato sin tener que recurrir al órgano judicial (resolución judicial), conforme a lo previsto en el artículo 1428 del Código Civil $^{52}$ o a la intimación (resolución por intimación), según lo establecido en el artículo 1429 del Código Civil. ${ }^{53}$

Como señala Bianca: "El derecho de receso que las arras confieren a ambas partes se ejercita mediante comunicación a la parte incumpliente. No se necesita por consiguiente proponer acciones judiciales o intimar, pero el presupuesto es siempre el incumplimiento o el retardo imputable y no de escasa importancia". ${ }^{14}$

49 ALFONSO RODRIGUEZ, María Elvira, Op. Cit., p. 127.

50 TRIMARCHI, Pietro, Istituzioni di Diritto Civile, Quindicesima Edizione, Giuffrè, Milano, 2003, p. 361.

51 Bianca señala que las arras confirmatorias también cumplen una función de garantía puesto que "la parte que las recibe tiene, en efecto, el poder de apropiarse la arras en caso de incumplimiento de la otra" (BIANCA, Massimo, Diritto Civile. 5 La responsabilità, Op. Cit., p. 361).

52 O resolución arbitral conforme a lo previsto en la Octava Disposición complementaria del Decreto Legislativo 1071.

53 Las arras podrían incorporarse a una cláusula resolutoria expresa asi, por ejemplo, establecer que si el comprador no paga el precio hasta una fecha determinada, el vendedor podrá resolver el contrato haciendo suyas las arras (BIANCA, Massimo, Diritto Civile. 5 La responsabilità, Op. Cit., p. 367).

54 BIANCA, Massimo, Diritto Civile. 5 La responsabilità, Op. Cit., p. 367. 
Cumplen además una función de determinación anticipada de los daños que sufre la parte que recesa como consecuencia del incumplimiento de la otra parte. En este caso cumple una función análoga con la cláusula penal, de ahi que la doctrina hable de "arras penales".55 Sin embargo, hay diferencias con la cláusula penal, puesto que las "arras penales" no vinculan a la parte no incumpliente conforme se desprende del artículo 1479 del Código Civil. En efecto, la parte fiel podrá optar por resolver el contrato por la vía judicial (o arbitral) o extrajudicial, y exigir el resarcimiento de los daños y perjuicios sufridos como consecuencia del incumplimiento y en tal caso quien recibió las arras la retendrá dentro de los límites de su pretensión resarcitoria. ${ }^{56}$ En este caso "las arras mantienen su función de garantía del resarcimiento, que se manifiesta en el derecho de retenerlas hasta que venga la liquidación de los daños (quedando a salvo siempre el derecho a reclamar el daño excedente)".57

El artículo 1478 del Código Civil señala:

"Si la parte que hubiese entregado las arras no cumple la obligación por causa imputable a ella, la otra parte puede dejar sin efecto el contrato conservando las arras. Si quien no cumplió es la parte que las ha recibido, la otra puede dejar sin efecto el contrato y exigir el doble de las arras".

Las arras pueden ser entregadas por una de las partes pero confieren a ambas partes la facultad de receso en caso de incumplimiento de la contraria. Si quien incumple es la parte que las ha recibido, la otra puede recesar y "exigir el doble de las arras", vale decir reclamar la devolución de las arras entregadas y "exigir" el pago de una cantidad similar como penalidad. No obstante, es perfectamente posible que al momento de concluir el contrato ambas partes se entreguen recíprocamente las arras (arras recíprocas) o las entreguen a un tercero depositario. ${ }^{58}$

\section{VIII.EL PACTO DE RETROVENTA EN LA COMPRAVENTA}

\section{De conformidad con el artículo 1586 del Código} Civil:

"Por la retroventa, el vendedor adquiere el derecho de resolver unilateralmente el contrato, sin necesidad de decisión judicial".

La redacción del artículo citado puede dar lugar a confusiones. Para Manuel de la Puente y Lavalle el pacto de retroventa es una condición resolutoria potestativa adherida al contrato de compraventa. ${ }^{59}$ Para Mario CastiIlo Freyre "el pacto de retroventa implica una cláusula resolutoria que se conviene a favor del vendedor".60 De la Puente y Lavalle se refiere a lo que debe ser la retroventa y Castillo Freyre a lo que termina siendo la retroventa en el Código Civil.

Conforme al artículo citado parecería que el pacto de retroventa es aquel pacto accesorio de la compraventa que confiere al vendedor

55 La doctrina se ha dividido entre una clasificación tripartita de las arras (confirmatorias, penales y penitenciales) y entre una clasificación bipartita (confirmatorias y penitenciales). Nuestro Código Civil parece inclinarse por una clasificación bipartita: arras confirmatorias y arras de retractación (penitenciales), aunque atribuyendo a las primeras una doble función.

56 "Artículo 1479: Si la parte que no ha incumplido la obligación prefiere demandar la ejecución o la resolución del contrato, la indemnización de daños y perjuicios se regula por las normas generales".

57 SCOGNAMIGLIO, Renato, Teoria General del Contrato, Bogotá, Universidad Externado de Colombia, 1991, p. 201.

58 También las arras de retractación podrían ser entregadas por ambas partes (arras recíprocas) o ser entregadas a un tercero.

59 DE LA PUENTE Y LAVALLE, Manuel, Estudios sobre el contrato de compraventa, Gaceta Juridica, Lima, 1999, p. 238.

60 CASTILLO FREYRE, Mario, Comentarios al Contrato de Compraventa, Gaceta Jurídica, Lima, 2002, p. 275. 
la facultad de receso ad nutum ${ }^{61}$, sin embargo esto no es así.

El receso no debe ser confundido con la retroventa, pues esta es una condición resolutoria potestativa que, además, debe operar de manera retroactiva, es decir desde el momento de la celebración del contrato de compraventa, lo cual significa que el acto nunca produjo efectos.

Coincidimos con De la Puente cuando señala:" la retroactividad es esencial para el funcionamiento del pacto de retroventa respecto a terceros, para la validez de dicho pacto sería necesario que al estipularlo las partes establecieran, en cada caso, la retroactividad del mismo".62 En la legislación italiana la "compraventa con pacto de rescate" es un contrato sujeto a condición resolutiva potestativa ${ }^{63} y$, los efectos de la verificación de la condición operan retroactivamente (artículo 1360 del Código Civil italiano).

Por lo expuesto, en el Perú, solo habrá pacto de retroventa cuando las partes pacten en contra del artículo 177 del Código Civil estableciendo que la resolución operará retroactivamente, si ello no ocurre estaríamos frente a un receso convencional y, por tanto, no sujetos a las reglas del pacto de retroventa del Código Civil.

\section{LA NATURALEZA DEL RECESO}

El receso ad nutum es el acto jurídico unilateral en virtud del cual una parte del contrato dispone, sin necesidad de expresar una causa, su disolución. ${ }^{64} \mathrm{El}$ ejercicio del receso supone la terminación anticipada del contrato. Se trata de una acto jurídico con efectos extintivos que se encuentra dentro de la categoría de los "negocios jurídicos de segundo grado" puesto que opera sobre otro negocio jurídico pre existente. ${ }^{65}$

Según algunos autores la cláusula que prevé el receso sería calificada como una opción de contrato resolutorio (de mutuo disenso). ${ }^{66} \mathrm{De}$ acuerdo con Sirena, en posición que compartimos, "(...) la cláusula de receso puede preveer una opción de pacto resolutorio, si las partes asillo han querido, pero puede preveer también un autónomo negocio jurídico unilateral resolutorio". ${ }^{67}$

El receso supone una declaración de voluntad de carácter recepticio, en principio, con libertad de forma ${ }^{68}$, salvo que las partes hayan previsto una forma determinada. ${ }^{69}$ No obstante, por ejemplo Bianca sostiene que se requiere la misma forma prescrita para el contrato que se recesa. ${ }^{70}$ En nuestro ordenamiento jurídico la posición del autor italiano encontraría susten-

61 Al respecto Castillo Freyre reconoce que la facultad de resolver puede ser ejercitada sin expresión de causa (CASTILLO FREYRE, Mario, Comentarios al Contrato de Compraventa, Op. Cit., p. 276).

62 DE LA PUENTE Y LAVALLE, Manuel, Estudios sobre el contrato de compraventa, Ob. Cit., p. 239.

63 TRIMARCHI, Pietro, Istituzioni di Diritto Civile, Op. Cit., p. 405. En el mismo sentido TORRENTE, Andrea y SCHLESINGER, Pietro, Op. Cit., p. 653.

64 Se diferencia de la revocación en cuanto esta extingue los efectos de un acto jurídico unilateral (así, por ejemplo, la revocación de un poder) mientras que el receso los de un contrato. Al respecto ver: SIRENA, Pietro, Effettie Vincolo. En: Op. Cit., p. 114. En nuestro ordenamiento la única excepción es la revocación del contrato de donación (artículo 1637 del Código (ivil).

65 En este sentido TABELLINI citado por RAVERA, Enrico, Op. Cit., p. 31.

66 Así GABRIELLI, citado por RAVERA, Enrico, Op. Cit., p. 32.

67 SIRENA, Pietro, Effetti e Vincolo. En: Op. Cit., p. 124.

68 Ver artículo 143 del Código Civil. En el caso del receso previsto en el artículo 1365 del Código Civil el aviso debe hacerse por vía notarial.

69 Ver artículo 1411 del Código Civil.

70 BIANCA, Massimo, Diritto Civile. 3 // Contratto, Op. Cit., p. 701. En el mismo sentido CARRESI, Franco, // Contratto. En: Trattato di Diritto Civile e Commerciale, XXI, t.2, Giuffrè, Milano, 1987, p. 844. 
to en el artículo 1413 del Código Civil.?' Debe resaltarse la necesidad que el titular declare su voluntad, no es suficiente un comportamiento del cual se desprenda la voluntad de no cumplir el contrato. ${ }^{72}$

La doctrina jurídica considera que debe imponerse al titular del derecho potestativo de receso el otorgamiento a la otra parte de un periodo de preaviso. En tal sentido, el efecto extintivo no se produce desde que la declaración de voluntad es conocida por el destinatario ${ }^{73}$ sino que se difiere al vencimiento del prescrito periodo de preaviso. No obstante, desde que la comunicación llega a conocimiento del destinatario el receso se torna irrevocable. Sin perjuicio de lo señalado, hay que reconocer ciertos casos donde la ley no exige el preaviso, así por ejemplo, en el caso del depósito conforme lo previsto en el artículo 1830 del Código Civil o del comodato según el artículo 1736 del Código Civil.

Como el Código Civil peruano no regula el receso, por lo que podríamos hablar de "receso atípico", no impone la obligación del preaviso, no obstante, creemos que en virtud del principio de buena fe (artículo1362 del Código Civil) debe concederse un "congruo" periodo de preaviso en interés de la parte que no recesa. ${ }^{74}$ Un caso excepcional en nuestro ordenamiento jurídico es el de los contratos de duración a plazo indeterminado en los cuales, conforme al artículo 1365 del Código Civil, el aviso debe ser remitido con una anticipación no menor a treinta días. Nuccia Parodi, señala que, salvo el caso del receso determinativo, en los otros casos no es, en principio, considerado necesario el pre aviso, aunque reconoce que la necesidad del preaviso podría derivarse de la obligación de comportarse de buena fe. ${ }^{75}$

Sirena, comentando los casos previstos en el Código Civil italiano ${ }^{76}$, señala: "la no observancia de tal plazo no genera un problema de ineficacia del receso, sino de incumplimiento de las obligaciones eventualmente nacidas del contrato, puesto que estas últimas no se extinguen en el interin: la parte que recese por tanto estará obligada al resarcimiento del daño o bien al pago de la penalidad eventualmente pactada"77

Para algunos autores el ejercicio del receso debe estar subordinado a un plazo determinado, tal como ocurre con la opción. Esta exigencia está ligada a la necesidad de garantizar la seguridad de la contratación y la certeza de las relaciones entre las partes. No obstante, no parece admisible establecer una solución única para todos los casos de receso, así por ejemplo, en el caso de los contratos de duración a plazo indeterminado no es admisible la inclusión de un término teniendo en cuenta que el ordenamiento jurídico no ve con buenos ojos los vínculos perpetuos. En este caso la tutela no está a favor de quien queda sujeta al receso sino de la parte de la relación vinculada sin límites temporales.

Cuando se ha establecido que el receso solo puede ejercerse a través de un pre aviso, debe tenerse en cuenta que este importa una carga del titular de la facultad de recesar de tal manera que su inobservancia hace ineficaz el receso.

71 "Las modificaciones del contrato original deben efectuarse en la forma prescrita para ese contrato".

72 En este sentido ver SACCO, Rodolfo y DE NOVA, Giorgio, Op. Cit., p. 694.

73 Por analogía se aplican los artículos 1373 y 1374 del Código Civil.

74 En este sentido ver BIANCA, Massimo, Diritto Civile. 3 // Contratto, Op. Cit., p. 705.

75 PARODI, Nuccia, Op. Cit., pp. 54-55.

76 El Código Civil italiano no tiene una norma general como el artículo 1365 del Código Civil peruano sino que prevé el receso de liberación en el contrato de suministro (artículo 1569), arrendamiento (artículo 1596), arriendo de cosa productiva (articulo 1616), agencia (artículo 1750), depósito (artículo 1771), comodato (artículo 1810), cuenta corriente (artículo 1833), entre otros.

77 SIRENA, Pietro, Effetti e Vincolo. En: Op. Cit., p. 133. 
Cuando se establece un término para el ejercicio del receso puede discutirse si es necesario que la comunicación al destinatario deba ser expedida dentro de dicho plazo o si dicha comunicación debe ser conocida por el destinatario dentro del plazo. Sin embargo, si tenemos en cuenta el artículo 1373 del Código Civil parecería que no basta la expedición dentro del plazo sino su conocimiento por el destinatario.

\section{LA FUNCIÓN DEL RECESO}

El artículo 1373 del Código Civil italiano señala:

"Si a una de las partes es atribuida la facultad de recesar el contrato, tal facultad puede ser ejercitada mientras el contrato no haya empezado a ejecutar.

En los contratos de ejecución continuada o periódica, tal facultad puede ser ejercitada también sucesivamente, pero el receso no tiene efectos para las prestaciones ya ejecutadas o en curso de ejecución (...)".

Como puede apreciarse el Código Civil italiano establece que el receso en las relaciones obligatorias contractuales con prestaciones de ejecución instantánea solo procede en la medida que estas aún no se hubieran empezado a ejecutar. Se entiende que al momento en que una parte inicia la ejecución del contrato manifiesta su voluntad de mantener firme el contrato $y$, por tanto, genera respecto de la otra parte la confianza sobre la subsistencia de la relación contractual. Como señala Nuccia Parodi: "En sustancia, el principio de ejecución expresa la voluntad implícita de una parte de no valerse del receso y genera una fuerte confianza en la contraparte respecto a la prosecución del contrato".78

Como indica Bianca:"En general, se tiene principio de ejecución cuando el efecto real se ha realizado en todo o en parte o cuando la prestación obligatoria ha sido, en todo o en parte, cumplida" ${ }^{\prime 79}$ Así, en los contratos con función traslativa, como es el caso por ejemplo, de la compraventa, la facultad de receso debe ser ejercitada antes que se produzca el efecto traslativo, salvo, obviamente, pacto distinto de las partes. Es decir, como afirma Bianca: "(...) las partes pueden disponer que el poder de receso sea ejercitable también después que el contrato haya sido en todo o en parte cumplido".80 En este caso, en el ordenamiento jurídico italiano se habla de "receso atípico".

Si nuestro ordenamiento jurídico tuviera una norma semejante a la italiana y si aceptamos que en virtud del artículo 949 del Código Civil el efecto traslativo es inmediato a la celebración del contrato con función translativa, entonces no podría, en principio, producirse el receso en un contrato de compraventa. ${ }^{81}$ Solo sería posible en el caso de la "compraventa obligacional" que es el caso, por ejemplo, de la compraventa de bienes inciertos, de bienes futuros y de bienes ajenos. ${ }^{82}$ Pero como en nuestro ordenamiento jurídico el receso es atípico, no hay objeción para que las partes prevean el receso en los contratos con función traslativa y se ejerza, incluso, cuando el efecto translativo ya se produjo.

El receso es propio de las relaciones obligatorias contractuales con prestaciones de ejecución duradera y, precisamente, permite terminar de manera anticipada la relación contractual. El receso no tiene efectos retroactivos, de tal manera que no afecta las prestaciones ya ejecutadas.

78 PARODI, Nuccia, Op. Cit., p. 52.

79 BIANCA, Massimo, Diritto Civile. 3 /l Contratto, Op. Cit., p. 702.

80 BIANCA, Massimo, Diritto Civile. 3 // Contratto, Op. Cit., p. 702. En el mismo sentido PARODI, Nuccia, Op. Cit., p. 51.

81 O cualquier otro contrato con función translativa.

82 Aunque nuestro Código Civil trata a la venta de bien ajeno como la promesa de la obligación o del hecho de un tercero. 
Como señalamos al inicio del presente ensayo, la función del receso legal puede ser de lo más variada, así se habla de recesos de liberación, recesos de autotutela y recesos de arrepentimiento.

Los recesos de liberación (o recesos determinativos) son aquellos atribuidos a la parte para disolver un vínculo contractual que de otra manera afectaría de manera intolerable su libertad, como sucede con los contratos de duración indeterminada. Si la parte no tuviera facultad de receso, se encontraría sujeta a un vínculo que no tendría fin, limitando considerablemente su libertad. Así, el artículo 1365 del Código Civil permite a cualquiera de las partes poner fin al contrato. ${ }^{83}$

El artículo 1365 del Código Civil señala lo siguiente:

"En los contratos de ejecución continuada que no tengan plazo convencional o legal determinado, cualquiera de las partes puede ponerle fin mediante aviso previo remitido por la via notarial con una anticipación no menor de treinta dias. Transcurrido el plazo correspondiente el contrato queda resuelto de pleno derecho".

De acuerdo con Roppo este tipo de receso responde a principios de orden público, por lo que la facultad de receso no puede ser excluida. ${ }^{84}$

La doctrina mayoritaria considera que en este caso el receso tiene por objeto evitar que si el vínculo contractual fuera ad infinitum afecte la libertad de las partes. En tal sentido, como hemos visto se habla de "receso de liberación". Para Sirena, en cambio, esa no sería la razón. El autor italiano señala: "En realidad parece que la razón justificativa de tal instituto sea simplemente la exigencia de conservar el contrato no obstante la indeterminación de su objeto, el cual no ha sido definido por las partes contratantes en uno de sus elementos esenciales: la duración" ${ }^{\prime \prime 5}$ y luego añade: "Tales normas no presuponen que las partes hayan querido estipular un contrato perpetuo, sino, al contrario, que ellas están desinteresadas en su duración" y luego concluye que no existe una prohibición para estipular contratos perpetuos ni que ello se desprenda de las normas sobre la facultad de receso en los contratos de duración, en tal sentido, es de la opinión que las partes pueden renunciar a su facultad de recesar.

Los recesos de autotutela son aquellos que la ley atribuye a las partes para consentirles reaccionar frente a defectos genéticos o funcionales del contrato, especialmente cuando se refiere al equilibrio sinalagmático de las prestaciones, tal como el receso a favor de la parte que no tiene un interés apreciable a la ejecución de la prestación parcialmente imposible conforme con el artículo 1316 del Código Civil. Otro supuesto es el previsto en el artículo 1478 del Código Civil. Se habla entonces de un receso impugnatorio.

Pueden ser también hechos sobrevinientes que modifican algún elemento significativo del contrato, colocando a las partes o a una de ellas frente a un vínculo contractual distinto al originalmente asumido. Un caso es el previsto en el artículo 1736 del Código Civil que faculta al comodante a solicitar la devolución del bien antes de cumplido el plazo si lo necesitara con urgencia imprevista. Hay casos en los cuales el receso está previsto como autotutela de quien sufre el ius variandi de la contraparte. ${ }^{86}$

83 Carresi no considera este supuesto como una facultad de receso (CARRESI, Franco, // Contratto. En: Op. Cit., p. 845). Hay casos en que la facultad de receso solo se atribuye a una de las partes, asi en el contrato de trabajo, que es de plazo indeterminado, el empleador no cuenta con la facultad de receso, si bien el trabajador sí goza de dicha facul$\operatorname{tad}$ (renuncia).

84 ROPPO, Vincenzo, // Contratto. En: Op. Cit., p. 646.

85 SIRENA, Pietro, Effetti e vincolo. En: Op. Cit., p. 117.

86 Ver al respecto BARCHI VELAOCHAGA, Luciano, El ius variandi en los contratos para la prestación de servicios públicos de telecomunicaciones. En: Derecho \& Sociedad, No. 26, 2006, p. 187 y ss. 
Esta facultad de receso no se remite al mero arbitrio del titular, sino que es ejercitada en presencia de determinados presupuestos, fuera de los cuales el receso no se justificaría. Este receso de autotutela procede, incluso, respecto de contratos con plazo determinado cuyo término final aún no ha vencido.

De acuerdo con Sirena las normas que regulan el receso impugnatorio admiten pacto en contrario siempre que no exista una norma expresa que lo impida o bien por la peculiaridad de un tipo contractual singular, como sería el caso del derecho de receso a favor del trabajador en el contrato de trabajo. ${ }^{87}$

Los recesos de arrepentimiento son aquellos que la ley atribuye a una parte sin vincularla a ningún presupuesto, sino solo porque considera oportuno consentir a esta cambiar de idea respecto al contrato concluido, de arrepentirse y convertir este arrepentimiento en un acto capaz de liberarla de un vínculo contractual que ya no le agrada. Así, por ejemplo, en el caso del mandato con representación previsto en el artículo 1808 del Código Civil. ${ }^{88}$

Este tipo de receso permite a su titular terminar anticipadamente el contrato porque ha perdido interés en su continuación (receso de arrepentimiento o ius se poenitendi). En este sentido Sirena señala: "El receso puede constituir el instrumento para reservar a una de las partes una nueva valoración de la conveniencia del negocio". ${ }^{89}$

Como advierte Roppo, en los contratos de duración el receso significa: "Valorar, después de haber disfrutado de la operación por un cierto tiempo, que dicho periodo de disfrute es suficiente, y que disfrutar la operación por un periodo ulterior no sería coherente con el propio interés ${ }^{\prime 90}$, en tal sentido el receso no tiene efecto retroactivo y por tanto no produce efectos respecto a las prestaciones ya ejecutadas.

De acuerdo con Nuccia Parodi: "el receso parece más bien asegurar una posibilidad de repensar frente a contratos en orden a los cuales una parte no haya aún verificado las consecuencias de la operación (o haya concluido un contrato con técnicas agresivas, cuando se trata de receso de protección".91 Para la autora la facultad de receso permite a su titular "(...) meditar mejor sobre la oportunidad y sobre la conveniencia del negocio y de la operación económica objeto del contrato, pero también controlar que los bienes transferidos no tengan cargas que alteren el valor pactado; obtener financiamiento; concluir acuerdos con terceros necesarios para poder "entrar» definitivamente en el negocio, etc.".92

Como puede advertirse estos intereses pueden ser tutelados a través de otros mecanismos jurídicos, como por ejemplo, la opción. En efecto, en virtud del contrato de opción una parte queda vinculada a su declaración de celebrar en el futuro un contrato definitivo y la otra, el titular de la opción, tiene el derecho exclusivo de celebrarlo o no. La diferencia fundamental es que con el receso el titular medita con el contrato ya concluido, mientras que con la opción la meditación se produce antes de su conclusión. El titular de la opción debe expresar su intención de ejercerla, si guarda silencio el contrato (definitivo) no se concluye. En el receso si su titular calla el contrato continúa, debe expresar su voluntad solo si quiere dejar sin efecto el contrato.

87 SIRENA, Pietro, Effetti e vincolo. En: Op. Cit., p. 118.

88 "Artículo 1808. - En el mandato con representación, la revocación y la renuncia del poder implican la extinción del mandato".

89 SIRENA, Pietro, Effettie vincolo. En: Op. Cit., p. 119.

90 ROPPO, Vincenzo, // Contratto. En: Op. Cit., p. 547.

91 PARODI, Nuccia. Op. Cit., p. 9.

92 PARODI, Nuccia. Op. Cit., p. 42. 


\section{LOS EFECTOS DEL RECESO}

El receso, al igual que el mutuo disenso o la resolución, no extingue el contrato considerado como acto. En efecto, el contrato como acto se agota en el tiempo y lo que subsisten son sus efectos, con el receso, el mutuo disenso o la resolución lo que se extingue son los efectos que dicho contrato produjo o se impide que se produzcan si aún no se produjeron, así en este último caso si el contrato estuviera sujeto a condición suspensiva.

Los efectos dependerán fundamentalmente del tipo de receso. Si se recesa un contrato de ejecución instantánea que haya tenido inicio de ejecución, entonces, salvo acuerdo en contrario, la extinción de los efectos jurídicos es retroactivo desde la celebración del contrato (ex tunc), quedando a salvo los derechos de terceros (ocurre algo similar a la rescisión). En tal sentido, deberán restituirse las prestaciones ejecutadas: al extinguirse la causa del desplazamiento patrimonial de manera sobreviniente (condictio ob causam finitam) entonces se está frente a un supuesto de desplazamiento patrimonial sin causa y, por tanto, se genera la obligación de restitución (fuente heterónoma de obligaciones).

En cambio, en el caso del receso de contratos de duración la extinción de los efectos jurídicos se produce desde el receso, es decir ex nunc, por lo que no habrá restitución de las prestaciones ya ejecutadas. No obstante, las partes podrian convenir que el receso tenga efecto respecto a las prestaciones ya ejecutadas o en curso de ejecución. ${ }^{93}$

En el receso se excluye la posibilidad de la reparación por la lesión del interés positivo y, salvo el caso del receso determinativo y del receso de autotutela donde no cabe indemnizar a la otra parte en caso de ejercitarlos, en los demás casos solo podría proceder la reparación por la lesión del interés negativo. En efecto el ejercicio del receso constituye el ejercicio de un derecho potestativo y, por tanto, no conlleva obligación de indemnizar a la otra parte. Es en este sentido que Cándido Paz-Ares afirma: "Las cláusulas de terminación ad nutum son cláusulas de terminación sin coste". ${ }^{\prime 4}$

El interés positivo es el interés a la ejecución del contrato, en tal sentido cuando se repara la lesión del interés positivo la indemnización debe ser tal de colocar a la parte lesionada en la misma situación económica que se habría encontrado en caso que el cumplimiento se hubiera verificado. El resarcimiento del interés positivo se puede describir en términos de daño emergente y lucro cesante. ${ }^{95}$

El daño emergente es la pérdida patrimonial del acreedor. El lucro cesante es el incremento patrimonial neto que el acreedor habría obtenido si el contrato se hubiera cumplido. Ello se determina por la diferencia de valor entre la prestación incumplida y la prestación debida por la parte fiel neta de los gastos. Así, por ejemplo, supongamos que por incumplimiento del vendedor se resuelve el contrato de compraventa de un departamento. Si el valor del departamento es de 100 superior al precio pactado que es de 80 , el comprador podrá pretender la diferencia (100 - 80) a título de lucro cesante, detrayendo posteriormente los gastos a su cargo. ${ }^{96}$

El interés negativo es el interés de la parte a no estipular un contrato destinado a tonarse ineficaz. La reparación del interés negativo tiende a colocar a la parte fiel en la situación económica

93 SIRENA, Pietro, Effettie vincolo. En: Op. Cit., p. 135.

94 PAZ-ARES, Cándido, Op. Cit., p. 31.

95 FRANZONI, Massimo, /l danno risarcibile. En: Trattato della responsabilita civile, Giuffré, Milano, 2004, pp. 89-90.

96 BIANCA, Massimo, Diritto Civile. 5 La responsabilità, Ob. Cit., p. 297. El valor que se toma en consideración es el de mercado, salvo que el acreedor logre probar que para él el valor es superior (por ejemplo, que demuestre que habria revendido el bien a un tercero por un precio $X$, superior al de mercado). 
en la cual se habría encontrado si el contrato no se hubiera celebrado. El resarcimiento del interés negativo también comprende el daño emergente y el lucro cesante. Abarca, fundamentalmente, los gastos en los que incurre el contratante fiel para celebrar el contrato no concluido: son los llamados daños de confianza y, también, el valor económico de las ocasiones perdidas por confiar en la celebración del contrato.

La doctrina italiana es pacífica en considerar que en el receso el resarcimiento de daños es generalmente excluido ${ }^{97}$, sin embargo, podríamos preguntarnos si cuando las partes prevén una "contraprestación" en caso de ejercer la facultad de receso ello no constituye una "pena convencional". Bianca al respecto señala "la multa penitencial no representa una penalidad en cuanto el acto de receso no constituye ni presupone un incumplimiento de quien recesa, quien ejercita un derecho del que es titular".98

Nuccia Parodi es enfática en sostener que no es posible considerar la "multa penitencial" como una "pena convencional" sino "una verdadera y propia contraprestación dirigida a mantener indemne a la parte que queda sujeta al receso de la pérdida de chances, derivadas de la imposibilidad de emprender tratativas con otros sujetos y de la necesidad de asegurar la propia disponibilidad del cumplimiento". ${ }^{\prime 9}$ En tal sentido, si se conviene una "contraprestación" por conceder la facultad de receso, esta debería ser de tal monto que permita compensar la lesión del interés negativo.

Respecto al contrato de agencia la jurisprudencia italiana ha señalado: "En tema de contrato de agencia, dado que el ejercicio, por parte del proponente, de la facultad de recesar ad nutum de la relación, salvo el deber de pre aviso, no constituye incumplimiento contractual, el daño sufrido por el agente por el receso no es resarcible".100

Teniendo en cuenta lo señalado, de acuerdo con Nuccia Parodi "cuando se prevé un receso, la parte que puede sufrirlo debería abstenerse de confiar en la ejecución del contrato y debería por tanto evitar tener comportamientos (o estipular otros contratos) que sobre esa confianza podrían se celebrados". ${ }^{101}$ En una relación contractual el deudor incurrirá probablemente en una serie de gastos $y$, probablemente tendrá que celebrar contratos con terceros (proveedores) con el fin de ejecutar las prestaciones a su cargo. En tal sentido, parece razonable preveer una contraprestación por otorgar la facultad de recesar que cubra, por lo menos, los daños negativos $y$, en los contratos con terceros preveer, en la medida de lo posible, también el receso.

De acuerdo con Nuccia Parodi cuando "las partes hayan previsto una alternativa al cumplimiento pactado, hayan disciplinado (por tanto programado) la resolución, estableciendo que la salida del contrato determine consecuencias en orden al cese de la confianza dada a una parte y estableciendo el costo (así calculando de alguna manera también la utilidad que una parte esperaba de la ejecución del contrato o el daño que puede derivar, directa o indirectamente, del cese de la relación), no se puede afirmar que se trate propiamente de un receso". ${ }^{102}$ De acuerdo con la autora italiana en ese caso estaríamos frente a un way out o lo que ella llama "salida programada del contrato".

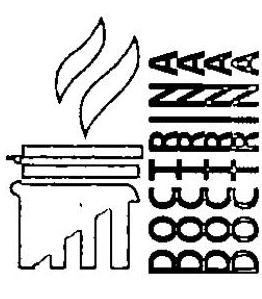

97 Ver PARODI, Nuccia, Op. Cit., p. 38.

98 BIANCA, Massimo, Diritto Civile. 3 // Contratto, Op. Cit., p. 706.

99 PARODI, Nuccia, Op. Cit., p. 50.

$100 \mathrm{ACHILLI}$, Vito y otros, // Contratto di agenzia. En: / contratti di distribuzione. A cura di Giuseppe Cassano, Giuffrè, Milano, 2006, p. 303.

101 PARODI, Nuccia, Op. Cit., p. 123.

102 PARODI, Nuccia, Op. Cit., p. 122. 
En España Rodríguez Marín ${ }^{103}$ sostiene que aquel que se desiste (recesa) está obligado a resarcir el perjuicio que se le haya causado a la otra parte, aunque dicho autor parece sustentar su opinión solo en el artículo 1594 del Código Civil español referido al receso en el contrato de obra, del que nos ocuparemos más adelante.

\section{EL CONTRATO DE OBRA COMO MODALIDAD DEL CONTRATO DE PRESTACIÓN DE SERVICIOS}

\section{El tipo contractual}

De acuerdo con Vincenzo Roppo "el tipo contractual es un modelo de operación económica, actuada mediante contrato, notoria y difundida en la vida de relación".104 Así, por ejemplo, la compraventa es un tipo contractual y es la operación económica donde las partes intercambian la titularidad de la propiedad sobre un bien por dinero.

El tipo contractual puede ser más o menos elástico. Así Roppo señala que el tipo es inelástico cuando "comprende todos los elementos que componen el objeto (o el contenido) del contrato: define la prestación, establece que debe haber una contraprestación, define también esta contraprestación". ${ }^{105}$ Este sería el caso de la compraventa que, en el artículo 1529 del Código Civil, su tipo se identifica por tres elementos: (i) la naturaleza de la prestación: la transferencia de la titularidad de la propiedad ${ }^{106}$; (ii) la necesidad de contraprestación (onerosidad); (iii) la naturaleza de la contraprestación: precio en dinero.

Hay casos de tipos más elásticos que se definen, ya no sobre la base de tres elementos sino

103 RODRIGUEZ MARIN, Concepción, Op. Cit., p. 216 Op. Cit., p. 445.

105 ROPPO, Vincenzo, // Contratto. En: Op. Cit., p. 425. piedad y de cualquier otro derecho. piedad y de cualquier otro derecho. de dos o de uno solo. ${ }^{107} \mathrm{El}$ arrendamiento, por ejemplo, que en el artículo 1666 del Código Civil, está definido por: (i) la naturaleza de la prestación del arrendador: la cesión temporal en uso de un bien; y, (ii) de la necesaria presencia de la contraprestación a cargo del arrendatario, pero su naturaleza puede ser variada, es decir, la renta puede ser una suma de dinero o un bien fungible. Así, si una parte asume la prestación del arrendador (cesión temporal en uso de un bien) pero sin contraprestación se sale del tipo arrendamiento y se entra en el tipo comodato (artículo 1728 del Código Civil; cesión en uso gratuito).

El mandato tiene una mayor elasticidad: solo es decisiva la naturaleza de la prestación del mandatario, puede haber o no contraprestación y en cualquiera de ambos casos estamos frente al mismo tipo (mandato oneroso o mandato gratuito). Si hay contraprestación puede ser de cualquier naturaleza.

\section{El contrato de prestación de servicios}

El artículo 1755 del Código Civil define la prestación de servicios de la siguiente manera:

"Por la prestación de servicios se conviene que éstos o su resultado sean proporcionados por el prestador al comitente".

Podemos decir que el contrato de prestación de servicios está definido solo por la naturaleza de la prestación: "proporcionar servicios" o "proporcionar el resultado de los servicios", pero no es necesaria la contraprestación, de tal manera que el contrato de prestación de servicios puede con prestaciones recíprocas (oneroso) o con

104 ROPPO, Vincenzo, // Contratto. En: Op. Cit., p. 419. En el mismo sentido BIANCA, Massimo, Diritto Civile. 3 // Contratto,

106 En otras legislaciones, como la italiana (el articulo 1470 del Codice Civile), la transferencia de la titularidad de la pro-

107 En otras legislaciones, como la italiana (el artículo 1470 del Codice Civile), la transferencia de la titularidad de la pro- 
prestación a cargo de una sola de las partes: el prestador (gratuito).

En el contrato de prestación de servicios la prestación puede consistir en: (i) "proporcionar servicios" o (ii) "proporcionar el resultado de los servicios".

En puridad, podríamos decir que en virtud del contrato de prestación de servicios el prestador siempre se obliga a una prestación de hacer. ${ }^{108}$ En las relaciones obligatorias con prestación de hacer podemos distinguir dos subespecies:

1. Las encaminadas a la producción de un resultado. Aquí podemos identificar dos variantes:

(i) casos en que la prestación de hacer está dirigida a la transformación de la materia así, por ejemplo, la prestación del carpintero en la construcción de un mueble. En estos casos el objeto de la relación obligatoria es una prestación de hacer y el dar con el que concluye asume una carácter instrumental respecto la realización de la prestación de hacer, y;

(ii) casos en que la prestación no está dirigida a la transformación de la materia sino a la producción de una utilidad distinta a la cosa. En estos casos podría ser necesaria también la modificación material de las cosas pero solo es un elemento instrumental al fin principal que es la aseguración del servicio final. Este sería el caso, por ejemplo, de la prestación del servicio de mantenimiento donde la actividad del prestador consiste en mantener la eficiencia de una cosa o también el de prestación del servicio de limpieza. En estos casos el empleo de medios materiales y de energía laboral está dirigida a la obtención del resultado final. ${ }^{109}$
En cualquiera de las dos variantes el resultado está in obligatione.

2. Las que constituyen un "puro hacer". En estos casos la prestación de hacer supone únicamente el empleo de energía laboral dirigida a la obtención de un resultado, pero este no está in obligatione. Mientras que en las primeras es posible aislar materialmente el resultado de la actividad en este caso el resultado no se distingue de la actividad. Este sería el caso, por ejemplo, de los servicios que brinda un abogado en un proceso judicial respecto del cual se obliga frente a su cliente a patrocinarlo bajo criterios de escrupuloso profesionalismo pero no a obtener una sentencia favorable.

Esto nos lleva a la distinción entre obligaciones de resultados y obligaciones de actividad (o de medios). Obligaciones de actividad son aquellas en las cuales la prestación debida consiste en el despliegue de una actividad del deudor dirigida a proporcionar, de forma mediata, la satisfacción del interés del acreedor, o lo que es lo mismo, en el desarrollo de una conducta diligente encaminada a conseguir el resultado previsto por el acreedor al contratar. El deudor se obliga a una actuación diligente que posibilite al acreedor obtener un resultado el cual, sin embargo, no está in obligatione.

Obligaciones de resultado, en cambio, son aquellas en las que el deudor se obliga a proporcionar de forma directa e inmediata la satisfacción del interés del acreedor, mediante la obtención de un resultado pactado que integra la prestación, un resultado que está in obligatione. Su cumplimiento o incumplimiento depende directamente de la producción o no del resultado.

La relevancia de la distinción entre las obligaciones de actividad y resultado se sitúa, funda-

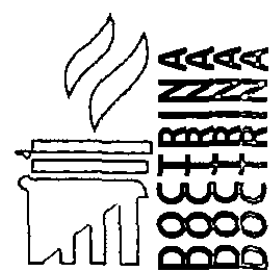

108 Nuestro Código Civil mantiene la clasificación tradicional de las obligaciones basada en la prestación que las divide en: obligaciones con prestación de dar, hacer y no hacer. Es con la regulación de cada una de ellas que se inicia el Libro de Obligaciones. El contrato con prestación se servicios, y como veremos todas sus modalidades, genera una obligación con prestación de hacer a cargo del prestador.

109 MASCARELlO, Carmela, /I Diritto Privato Oggi, Serie a cura di Paolo Cendom, Giuffrè, Milano, 2002, p. 74. 
mentalmente, en el terreno del cumplimiento de la obligación. Las obligaciones de actividad y de resultado son dos modos distintos de configurar-definir el cumplimiento de las relaciones obligatorias con prestación de hacer. En otras palabras, lo que el deudor debe hacer para cumplir, en uno $u$ otro caso, no es lo mismo. Como señala Franzoni la distinción no es relevante "para definir el régimen de responsabilidad del deudor-objetivo en las obligaciones de resultado, subjetivo en las obligaciones de medios-sino para establecer a qué cosa se encuentra obligado el deudor (...)".110

En efecto, la distinción entre las obligaciones de actividad y de resultado fue utilizada por la doctrina francesa contemporánea para resolver la contradicción que parece existir entre los artículos 1147 y 1137 del Código Civil francés respecto a la carga de la prueba de la culpa." Así según el artículo $1147^{112}$ la culpa se presume y solo la causa no imputable puede eximir al deudor de responsabilidad. En cambio, el articulo $1137^{113}$ el deudor quedaría liberado de responsabilidad probando su diligencia. Para Demogue, el artículo 1137 se refería únicamente a las obligaciones de medio 114 ("de moyen"), mientras el artículo 1147 a las obligaciones de resultado ("de résultat").

Una contradicción similar parece encontrarse entre los artículos 1218 y 1176 del Código Civil italiano. Un sector de la doctrina italiana considera que el artículo 1218 consagra la responsabilidad objetiva aplicable a las obligaciones de resultado y el 1176 , la responsabilidad subjetiva, aplicable a las obligaciones de medios. ${ }^{115}$ Para Franzoni la distinción no es relevante para definir el régimen de responsabilidad del deudor: objetivo en las obligaciones de resultado, subjetivo en las obligaciones de actividad, sino que lo es para establecer a qué se encuentra obligado el deudor. ${ }^{116}$

110 FRANZONI, Massimo, La responsabilidad en las obligaciones de medios y en las obligaciones de resultado. En: Themis. Revista de Derecho, No. 38, 1998, p. 84.

111 Ver respecto a la doctrina francesa MAZEAUD, Henri y León y TUNC, André, Tratado Teórico y Práctico de la Responsabilidad Civil y Contractual, Tomo Primero, Volumen II, Ediciones Juridicas Europa-América, Buenos Aires, 1962, p. 398 y ss. Ver LOBATO SÁNCHEZ, J. Miguel, Contribución al estudio de la distinción entre las obligaciones de medios y las obligaciones de resultado. En: Anuario de Derecho Civil, p. 651 y ss. CABANILLAS SÁNCHEZ, Antonio, Las obligaciones de actividad y de resultado, Bosch, Barcelona, 1993, p. 13 y ss.

112 «Le débiteur est condamné, s'il y a lieu, au payement de dommages et intérêts, soit à raison de linexécution de l'obligation, soit à raison du retard dans l'exécution, toutes les fois qu'il ne justifie pas que l'inexécution provient d'une cause étrangère qui ne peut lui être imputée, encore qu'll n'y ait aucune mauvaise foi de sa part».

113 «L'obligation de veiller à la conservation de la chose, soit que la convention n'ait pour objet que l'utilité dl'une des parties, soit qu'elle ait pour objet leur utilité commune, soumet celui qui en este chargeé à y apporter tous les soins d'un bon père de famille.

Cette obligation est plus ou moins étendue relativement à certains contrats, dont les effets, à cet égard, sont epliqués sous les titres quiles concernent".

114 La paternidad de la doctrina se le atribuye a Demogue (Ver LOBATO SÁNCHEZ, J. Miguel, Op. Cit., p. 651. CABANILLAS SÁNCHEZ, Antonio, Las obligaciones de actividad y de resultado, Op. Cit., p. 13). Demogue hablaba de "obligaciones de medio" sin la "s" final. Al respecto debe tenerse en cuenta que también existe en la doctrina un debate respecto a la terminología (Ver LOBATO SÁNCHEZ, J. Miguel, Op. Cit., p. 654 y ss. CABANILLAS SÁNCHEZ, Antonio, Las obligaciones de actividad y de resultado, Op. Cit., p. 17 y ss.).

115 Ver una explicación sobre la elaboración doctrinal italiana en VISINTINI, Giovanna, L'inadempimento e mora del debitore. En: /l Codice Civile Commentario. Diretto da Piero Schlesinger, Giufrè, Milano, 1987, p. 75 y ss. Ver también al respecto FERNÁNDEZ CRUZ, Gastón, Comentarios al artículo 1314 del Código Civil. En: Código Civil Comentado, Tomo VI, Gaceta Jurídica, Lima, 2004, p. 849 y ss.

116 En la doctrina nacional Osterling Parodi y Castillo Freyre se manifiestan contrarios a la distinción entre "obligaciones de medios" y "obligaciones de resultado" pero ubicándola dentro del tema de la responsabilidad civil (OSTERLING PARODI, Felipe y CASTILLOO FREYRE, Mario, El tema fundamental de las obligaciones de medios y de resultados frente a la responsabilidad civil. En: Derecho. Revista de la Facultad de Derecho de la Pontificia Universidad Católica del Perú, Número 53 , diciembre, 2000, p. 475 y ss.). 
A nuestro juicio el Código Civil peruano sigue la línea expresada por Franzoni. Como ocurre con la mayoría de Códigos Civiles, el peruano no regula específicamente la clasificación de "obligaciones de actividad" $y$ "obligaciones de resultado" y la doctrina no ha recurrido a la tesis de Demogue para salvar la aparente contradicción existente entre los artículos 1314 y 1315 del Código Civil, donde el primero parece acoger la responsabilidad subjetiva y el segundo la objetiva. ${ }^{117}$ No obstante, la distinción sí se encuentra recogida a propósito del contrato de prestación de servicios y es un elemento de distinción de sus modalidades (sub tipos), especialmente, del contrato de locación de servicios y del contrato de obra. Es decir, el Código Civil ha acogido la distinción para diferenciar el "contrato de locación de servicios" del "contrato de obra".

¿Cómo se determina si una obligación con prestación de hacer es de actividad o si es de resultado? La doctrina considera que hay que atender sucesivamente a los siguientes criterios ${ }^{118}$ :

1. Tratándose de relaciones obligatorias de fuente contractual el criterio a tomarse en cuenta será el de la voluntad de las partes. Así, un abogado podría obligarse frente a su cliente, por ejemplo, a patrocinarlo en un proceso judicial bajo criterios de escrupuloso profesionalismo pero no a obtener una sentencia favorable; no obstante también es posible que se obligue a obtener la sentencia favorable. ${ }^{119}$ No es exacto entonces afirmar que la obligación del abogado, del médico o de los "profesionales liberales" necesariamente es de medios.

2. Cuando las partes no precisan si la obligación es de actividad o de resultado, la doctrina y la jurisprudencia han establecido una serie de criterios, que pueden ser subjetivos u objetivos.

El carácter aleatorio del resultado (criterio objetivo) es el más invocado por la doctrina y la jurisprudencia. "En este sentido -como señala Lobato Gómez- se afirma que si la obtención de un resultado en símismo es aleatorio (...) sería una obligación de medios, pues no sería razonable garantizar un resultado de este tipo de hipótesis. Por el contrario, cuando el resultado considerado debe de ser normalmente alcanzado con el empleo de los medios de que dispone o que deberia disponer el deudor (...), la obligación sería normalmente de resultado". ${ }^{20}$ No obstante, no han faltado críticas para este criterio pues es difícil distinguir las obligaciones aleatorias de aquellas que presentan un riesgo normal.

El contrato con prestación de servicios es un género, es decir, una categoría compuesta por especies, el Código Civil, en su artículo 1756 las denomina "modalidades". ${ }^{21}$ Entre el género

117 FERNÁNDEZ CRUZ, Gastón, Comentarios al artículo 1314 del Código Civil. En: Código Civil Comentado, Tomo VI, Op. Cit., p. 858.

118 En este sentido LOBATO GÓMEZ, J. Miguel, Op. Cit., p. 697 y ss., CABANILLAS SÁNCHEZ, Antonio, Las obligaciones de actividad y de resultado, Op. Cit., p. 38 y ss.

119 Así, el abogado podría fijar sus honorarios por los servicios que brinda independientemente del resultado o fijarlos para el caso de obtener una sentencia favorable. También es posible establecer un honorario fijo que retribuya los servicios y un honorario de éxito en caso de obtener el resultado.

120 LOBATO GOMEZ, J. Miguel, Op. Cit., p. 702.

121 "Artículo 1756.- Son modalidades de la prestación de servicios nominados:

Locación de servicios.

El contrato de obra.

El mandato.

El depósito.

El secuestro".

"Artículo 1757.- Son también modalidades de la prestación de servicios, y les son aplicables las disposiciones contenidas en este capítulo, los contratos innominados de doy para que hagas y hago para que des". 
y las especies existe un elemento común que los vincula ¿cuál es el elemento común? Pues todos ellos son contratos constitutivos de una obligación con prestación de hacer, esto es lo que hace, que los tipos se superpongan. La diferencia es que algunas de esas modalidades generan para el prestador una obligación de actividad y otras, una de resultado.

Como bien señala Cabanillas Sánchez "el problema de la configuración de la obligación como de actividad o de resultado se plantea, sobre todo, a propósito de las obligaciones de hacer, ya que el objeto de la obligación de hacer puede ser el resultado pretendido por el acreedor o solo la actividad diligente del deudor encaminado a lograrlo. Habrá, por tanto, que tener en cuenta el compromiso asumido por el deudor de la obligación de hacer para solucionar el problema. La configuración de la obligación de dar y de no hacer es menos problemática, pues en ellas no se plantea la disyuntiva que surge cuando la obligación es de hacer". ${ }^{122}$ Es decir, las obligaciones con prestación de dar y aquellas con prestación de no hacer son siempre de resultado. En efecto, si por ejemplo, el deudor se obliga a entregar una suma de dinero solo cumple en la medida que la entregue (resultado). No importa qué tan diligente haya sido para ejecutar la prestación a su cargo, si no la ejecutara objetivamente se habría producido una lesión de crédito (habría inejecutado la prestación y podría encontrarse en una situación de incumplimiento o de retardo). El análisis de la diligencia empleada, en caso de lesión de crédito, solo sería necesario para determinar su responsabilidad.
De la Puente y Lavalle al respecto señala: "El planteamiento legislativo que se formula está inspirado en el Código Civil portugués ${ }^{123}$, que considera el contrato de prestación se servicios como una categoría genérica, cuyas modalidades son el mandato, el depósito y la empresa (locación de obra). Esta sistemática permite contemplar en un capitulo sobre disposiciones generales de la prestación de servicios todas las reglas que son comunes a los contratos de locación de servicios, contrato de obra, mandato, depósito y secuestro, evitándose innecesarias repeticiones al legislar cada contrato separadamente y destacar que todos ellos son miembros de una misma familia, cuya característica es prestar servicios, sin perjuicio que en las secciones destinadas a regular cada uno de dichos contratos nominados se consignen detalladamente las normas propias de ellos, asi como las que deroguen las disposiciones generales". 124

\section{El Contrato de obra y el contrato de locación de servicios}

Dos de las modalidades del contrato de prestación de servicios son el contrato de obra y el de locación de servicios.

\section{El artículo 1764 del Código Civil señala:}

\begin{abstract}
"Por la locación de servicios el locador se obliga, sin estar subordinado al comitente, a prestarle sus servicios por cierto tiempo o para un trabajo determinado, a cambio de una retribución".
\end{abstract}

122 CABANILLAS SÁNCHEZ, Antonio, Las obligaciones de actividad y de resultado, Op. Cit., p. 47.

123 "Articulo 1154.- Contrato de prestación de servicio es aquel en el que una de las partes se obliga a proporcionar a otra cierto resultado de su trabajo intelectual o manual, con o sin retribución".

"Articulo 1155.- El mandato, el depósito y el contrato de obra, regulados en los capítulos subsiguientes, son modalidades del contrato de prestación de servicios".

124 DE LA PUENTE Y LAVALLE, Manuel, Prestación de servicios. Exposición de motivos y comentarios. En: Código Civil. Exposición de Motivos y Comentarios, Tomo VI, Compiladora: REVOREDO DE MUR, Delia, Okura Editores, Lima, 1985, pp. 440-441. No creemos que sea muy evidente la intención del legislador del Código Civil de 1984 de "evitar repeticiones innecesarias", puesto que, por ejemplo, no se explicaria entonces la necesidad de regular la imposibilidad sobreviniente de la prestación en tres lugares distintos: 1) En el Libro de Obligaciones (articulo 1138 para las obligaciones con prestación de dar bien cierto y en los artículos 1154,1155 y 1156 para las obligaciones con prestación de hacer); 2) En el Libro de Fuentes de las Obligaciones (Contratos en General), así artículos 1431, 1432 y 1433; y, finalmente 3) En el contrato de compraventa en el artículo 1567. 
La locación de servicios está definida por: (i) la naturaleza de la prestación del locador: la prestación de un servicio; $y$, (ii) de la necesaria presencia de la contraprestación a cargo del comitente (retribución) que consiste en una suma de dinero. ${ }^{125}$

Por otro lado, el artículo 1771 del Código Civil define al contrato de obra, de la siguiente manera:

"Por el contrato de obra el contratista se obliga a hacer una obra determinada y el comitente a pagarle una retribución".

El contrato de obra está definido por: (i) la naturaleza de la prestación del contratista: la realización de una obra; y, (ii) de la necesaria presencia de la contraprestación a cargo del comitente (retribución) que consiste en una suma de dinero. ${ }^{26}$

Como puede apreciarse tanto en virtud del contrato de locación de servicios y como del contrato de obra se genera a cargo del prestador (locador o contratista) una obligación con prestación de hacer a cambio de una retribución, lo que los convierte en sub tipos de la prestación de servicios.

¿Qué distingue el contrato de locación de servicios del contrato de obra? Solé Resina responde: "De entre todos los criterios distintivos propuestos por la doctrina y la jurisprudencia, el que goza, en la actualidad, de mayor aceptación atiende al objeto de la obligación de hacer nacida del contrato y distingue si ésta compromete la prestación del trabajo en símismo considerado, no el resultado que produce (contrato de servicios), o si compromete el resultado sin consideración al trabajo que lo crea (contrato de ejecución de obra)".127 En palabras sencillas el "contrato de locación de servicios" genera a cargo del prestador (locador) una obligación de actividad y el "contrato de obra" a cargo del prestador (contratista) una obligación de resultado.

De acuerdo con Solé Resina la ejecución de una obra es "la creación de una cosa corporal o incorporal, susceptible de ser identificada del resto de las cosas a las que pueda quedar incorporada y con plena autonomía propia, fruto de la puesta en práctica de una determinada actividad encaminada a ella"128 y luego añade: "La principal característica del contrato de ejecución de obra, y la que permite distinguirlo de otros contratos de actividad, es la de originar una obligación de hacer dirigida a la creación de un nuevo objeto de derecho (una cosa ex novo)."129 En tal sentido para la autora española el contrato de obra genera una obligación con prestación de hacer a la que normalmente se le añade un dar, pero teniendo en cuenta que este dar es un instrumento del hacer.

La posición de Solé Resina parece restringir la idea de la ejecución de obra a la transformación de una cosa corporal o incorporal, siendo para nosotros más exacto lo señalado en el parágrafo 631 del B.G.B:

\section{"(...) 2. El objeto del contrato de obra puede ser la producción o la alteración de una cosa, o cualquier otro resultado producido por el trabajo o prestación de servicios" (el subrayado es nuestro).}

Es decir que en virtud del contrato de obra el contratista se obliga a "proporcionar el resultado de los servicios", lo cual comprende, pero no se limita a la producción o la alteración de una cosa. Este sería el caso, por ejemplo, del contrato de difusión publicitaria el cual puede ser definido

125 Si fuera gratuito no estaríamos frente a una locación de servicios sino frente a una prestación de servicios.

126 Si fuera gratuito no estaríamos frente a un contrato de obra sino frente a una prestación de servicios.

127 SOLÉ RESINA, Judith, Los contratos de servicios y de ejecución de obras. Delimitación jurisprudencial y conceptual de su objeto, Pons, Madrid, 1997, p. 14.

128 SOLÉ RESINA, Judith, Op. Cit., p. 94.

129 SOLÉ RESINA, Judith, Op. Cit., p. 95. 
como el "contrato que celebra el anunciante o una empresa de publicidad con el medio de difusión y por el cual, a cambio de una contraprestación en dinero generalmente tarifada (...), se inserta (...) un mensaje publicitario, para su divulgación en dicho medio de comunicación; mensaje o comunicación que se relacionan al interés de promoción de negocios del sujeto emisor y no al del titular del medio o soporte que éste se divulga".130 Este contrato genera para el titular del medio de comunicación una obligación de resultado, por ejemplo, la emisión televisiva y como señala Murguillo"esta forma de contratación se identiffca-por sus particularidades-con la locatio operis o "locación de obra", puesto que el titular del medio se compromete a la ejecución de una obra a su riesgo técnico y económico". ${ }^{131}$

Arias Schreiber reseñando las diferentes posiciones respecto a la distinción entre la locación de servicios y el contrato de obra señala: "Pero recientemente ha surgido una tercera posición, distintas a las anteriores, cuya raíz se encuentra en el Código Civil italiano de 1942 y que, a nuestro entender, es la que ha sido recogida en el Código Civil peruano de 1984" y luego agrega: "Su punto de partida está en la concepción delllamado appalto o contrata (artículos 1655 a 1677 del Código Civil italiano) en el cual la obra es tratada de un modo que calificaremos de preponderantemente «empresarials y que tiene especial aunque no exclusiva incidencia en el área de la construcción. Como consecuencia de esta tesis, resultaría que todos los actos que antiguamente estaban considerados como locación de obra y que se caracterizaban por su carácter artesanal e individual pasarian a integrar la locación de servicios (...)"132, en este orden de ideas el profesor sanmarquino considera que, por ejemplo, habría locación de servicios y no contrato de obra en los casos del sastre que confecciona un terno, de la confección de un juego de muebles, entre otros. Habría contrato de obra en los contratos en que predomine la actividad empresarial, como la construcción de un edificio, puente, carretera, etc.

El Código Civil italiano distingue el contrato "d'appalto" del contrato "di opera" por el hecho que en el primero la ejecución de la obra la realiza una mediana o gran empresa mientras que en el segundo el prestador de la obra es sustancialmente un pequeño empresario ${ }^{133}$ con trabajo propioy con el auxilio de pocos dependientes. En tal sentido, no puede sostenerse que este sea un criterio para distinguir la locación de servicios del contrato de obra como afirma Arias Schreiber. Así, de acuerdo con el Código Civil italiano el caso del sastre que confecciona un terno es un contrato "diopera" y el caso de la construcción de un edificio un contrato "d'appalto" y en ambos casos estamos frente a una obligación de resultado. En nuestro Código Civil, el contrato de obra comprende la ejecución de una obra tanto por una mediana o gran empresa como por un pequeño empresario.

Ahora bien, de acuerdo con el Código Civil, la prestación de servicios es el género y el contrato de obra es una especie de dicho género dónde estarían comprendidos todos aquellos contratos en virtud de los cuales el prestador se obliga a "proporcionar el resultado de los servicios" a cambio de una retribución, estos contratos se diferencian por la naturaleza del resultado que constituye su objeto. Así, por ejemplo, el contrato de difusión publicitaria y el contrato de transporte están incluidos en la categoria de la locatio operis pero se diferencian entre sí por la naturaleza del resultado ${ }^{134}$ : en el contrato de

130 MUGUILLO, Roberto Alfredo, Publicidad, Astrea, Buenos Aires, 2005, p. 95.

131 MUGUILLO, Roberto Alfredo, Op. Cit., p. 97.

132 ARIAS SCHREIBER PEZET, Max, Con la colaboración de CÁRDENAS QUIROS, Carlos, Comentarios al Contrato de Obra. En: Código Civil. Exposición de Motivos y Comentarios, Tomo VI, Compiladora: REVOREDO DE MUR, Delia, Okura Editores, Lima, 1985, p. 460.

133 MASCARELLO, Carmela, Op. Cit., p. 57. DE TILL_A, Maurizio, L'Appalto privato, Seconda edizione, Okura Editores, Milano 2007, p. 65 ,

134 Respecto al contrato de transporte y al contrato de "appalto", ver: TORRENTE, Andrea y SCHLESINGER, Pietro, Op. Cit., p. 685. 
difusión publicitaria el resultado es la emisión publicitaria (televisiva o radial) y en el contrato de transporte el transferir personas o cosas de un lugar a otro.

Como señala Roppo "el sentido fundamental del tipo está en determinar la reglas aplicables a las relaciones contractuales pertenecientes al tipo $(\ldots)^{\prime \prime 135}$ así, si la operación económica realizada por las partes se subsume en el tipo "compraventa" le serán aplicables a dicha operación las disposiciones establecidas en los artículos 1529 y siguientes del Código Civil. Entonces, teniendo en cuenta lo señalado, ¿les serán aplicables a todos los contratos en virtud de los cuales el prestador proporciona el resultado de sus servicios a cambio de una retribución; es decir, a los contratos incluidos en la categoría de la locatio operis, las disposiciones del contrato de obra previstas en los artículos 1771 y siguientes del Código Civil ${ }^{136}$ ? En tal sentido, ¿se le atribuye a quien "recibe el resultado" la facultad de receso ad nutum ex lege previsto en el artículo $1786 \mathrm{del}$ Código Civil?

Si el contrato tiene una tipificación legal ${ }^{137}$ específica como, por ejemplo, en el caso del mandato, la respuesta parece ser negativa. Pero si no la tienen la respuesta debería ser más bien afirmativa puesto que todos estos contratos se subsumen en el tipo del contrato de obra; dicho de otra manera, todos las modalidades de prestación de servicios que están incluidas en la categoría de la locatio operis que no tengan tipificación legal específica son, para nuestro Código Civil, "contratos de obra", que se diferencian entre sí por la naturaleza del resultado.
Esto incluye a aquellos contratos que tienen solo una tipificación social ${ }^{138}$ como, por ejemplo, al contrato de difusión publicitaria y al contrato de transporte terrestre. ${ }^{139}$

\section{XIII.EL RECESO LEGAL AD NUTUM EN EL CONTRATO DE OBRA}

Tanto en el contrato de locación de servicios como en el contrato de obra se ha previsto la facultad de receso. En el artículo 1769 del Código Civil a favor del locador, es decir, del obligado a la prestación de servicios, un receso legal por justa causa:

"El locador puede poner fin a la prestación de servicios por justo motivo, antes del vencimiento del plazo estipulado, siempre que no cause perjuicio al comitente.

Tiene derecho al reembolso de los gastos efectuados y a la retribución de los servicios prestados".

Dentro las normas que regulan el contrato de obra, encontramos el artículo 1786 del Código Civil el cual señala:

"El comitente puede separarse del contrato, aun cuando se haya iniciado la ejecución de la obra, indemnizando al contratista por los trabajos realizados, los gastos soportados, los materiales preparados y lo que hubiere podido ganar si la obra hubiera sido concluida".

El artículo citado prevé a favor del comitente, es decir al acreedor de la ejecución de la obra,

135 ROPPO, Vincenzo, // Contratto. En: Op. Cit., p. 420.

136 Obviamente solo aquellas que resulten aplicables puesto que hay disposiciones que resultan de aplicación solo a contratos de edificación.

137 Como señala Bianca: "El tipo contractual legal es un modelo de operación económica que se ha traducido en un modelo normativo, es decir en un modelo de contrato previsto y disciplinado por la ley" (BIANCA, Massimo, Diritto Civile. 3 /I Contratto, Op. Cit., p. 446).

138 "El tipo social es, en cambio, un modelo afirmado en la práctica de los negocios pero no regulado específicamente por la ley" (BIANCA, Massimo, Diritto Civile. 3 // Contratto, Op. Cit., p. 446).

$139 \mathrm{El}$ contrato de transporte terrestre se encontraba tipificado en el Código de Comercio, pero luego la Ley de TítulosValores (Ley 27287) derogó los artículos correspondientes. 
una facultad de receso. Se trata de un receso ad nutum ex lege establecido a favor del comitente; es decir, que no son relevantes los motivos que lleven al comitente a recesar. No se trata de una norma de orden público, por tanto, las partes pueden suprimir expresamente la facultad de receso ${ }^{140}$, incluso, se considera válida la cláusula que prevé el receso ad nutum a favor del comitente sin que el contratista tenga derecho a alguna indemnización. ${ }^{141}$

La facultad de receso puede ser ejercida por el comitente en cualquier momento aún si la ejecución de la obra ya se hubiese íniciado. La ley no exige una determinada forma para la comunicación del receso, salvo que ella hubiera sido prevista por las partes.

Una norma similar la encontramos en el artículo 1594 del Código Civil español:

"El dueño puede desistir, por su sola voluntad, de la construcción de la obra, aunque se haya empezado, indemnizando al contratista de todos sus gastos, trabajos y utilidad que pudiera obtener de ella".

Rodríguez Marin comentando el artículo citado señala que el precedente se encuentra en el artículo 1794 del Código Civil francés el cual dispone lo siguiente:

"Le maître peut résilier, par sa simple volonté, le marché à forfait, quoique l'ouvrage soit déjà commencé, en dédommageant l'entrepreneur de toutes ses dépendes, et tous ses travaux, et detout ce qu'il aurait pu gagner dans cette entreprise".
El artículo citado tiene una diferencia importante en relación al 1.594 del Código Civil español y al artículo 1786 del Código Civil peruano, pues utiliza la expresión "ajuste alzado"(le marchéa forfait), con lo que limita la facultad de receso a los contratos de obra celebrados bajo esa modalidad.

La sentencia del Tribunal Supremo español del 22 de junio de 1911 restringió la aplicación del artículo 1.594 del Código Civil español exclusivamente a los contratos sobre construcción de edificios por ajuste o precio alzado. ${ }^{142}$ Fueron tres los argumentos en los que se basó el Tribunal Supremo: (i) Por considerarse una modificación del artículo 1.256 del Código Civil español ${ }^{143}$; (ii) Por el tenor literal del propio artículo; y, (iii) Por la relación que guarda con el artículo que le precede: el 1.593. ${ }^{144}$ Rodríguez Marín contrario a esta posición señala: "(...) el ámbito de aplicación queda dirigido hacia cualquier clase de contrato de obra en general, sin diferenciación acerca de si es o no por ajuste o precio alzado"145, es decir, que debe considerarse aplicable a todo otro resultado. Por nuestra parte, no encontramos razón alguna para extender los argumentos de la sentencia del Tribunal Supremo español del 22 de junio de 1911 al Código Civil, por lo que el artículo 1786 del Código Civil no puede restringirse al contrato de obra por ajuste o precio alzado.

Finalmente, para Rodríguez Marín son razones de equidad la que justifican la incorporación del artículo 1.594 del Código Civil español. ${ }^{146}$

\section{XIV.LA INDEMNIZACIÓN EN CASO DE RECESO DEL CONTRATO DE OBRA}

140 DE TILLA, Maurizio, Op. Cit., p. 299.

141 DE TILLA, Maurizio, Op. Cit., p. 320.

142 RODRÍGUEZ MARÍN, Concepción, Op. Cit., nota (19), p. 315.

143 "La validez y el cumplimiento de los contratos no pueden dejarse al arbitrio de uno de los contratantes".

144 "El arquitecto o contratista que se encarga por un ajuste alzado de la construcción de un edificio u otra obra (...)".

145 RODRÍGUEZ MARÍN, Concepción, Op. Cit., p. 322.

146 RODRIGUEZ MARÍN, Concepción, Op. Cit., p. 333. 
De acuerdo con el artículo 1786 del Código Civil el comitente que ejerce el receso debe indemnizar al contratista por los gastos incurridos, los servicios prestados y por la ganancia dejada de percibir. De acuerdo con la doctrina "tal indemnización, previendo sea el daño emergente (trabajos ejecutados y gastos) sea ellucro cesante (ganancia dejada de percibir), asume consecuencias que se sobreponen a aquellas de la resolución por incumplimiento". 147

En tal sentido, el comitente debe indemnizar al contratista por el daño emergente, esto es y en la medida que se presenten:

(i) Los gastos incurridos hasta el momento del receso;

(ii) Los trabajos ejecutados; es decir, la parte de la obra ejecutada hasta el momento del receso. En este caso a decir de Rodrígueż Marín se deben distinguir distintos supuestos en función de la modalidad contratada, "(...) si estamos ante una obra contratada por ajuste o precio alzado, se apreciará el valor de lo hecho, en razón de lo que falta por ejecutar y del precio originario. Si por precio unitario se aplicará éste. $Y$ si es por administración sólo comprenderá lo relativo a la obra ejecutada"148; $y$,

(iii)Los materiales preparados.

En cuanto a la ganancia dejada de percibir (lucro cesante), debemos tener en cuenta lo señalado anteriormente respecto a la-indemnización de los daños positivos. Esta es la que procede en el caso de una resolución por incumplimiento, el cual implica una lesión del interés positivo de la parte no incumpliente.

Al respecto señala Trimarchi: "el principio fundamental es que el resarcimiento debe colocar al contratante lesionado en una situación económica equivalente a aquella en la cual se habría encontrado si el contrato hubiese sido exactamente cumplido: se trata, es decir, de hacerle obtener el valor del negocio, sobre el cual había confiado. El resarcimiento asi concebido tiene por objeto, se dice el interés positivo (o interés al cumplimiento)". ${ }^{149}$

Al concepto del resarcimiento por lesión del interés positivo se opone el resarcimiento por lesión del interés negativo, el cual está dirigido a colocar al contratante lesionado en una situación equivalente a la que se encontraría si el contrato no hubiese sido celebrado. Como señala Trimarchi: "ello significa compensarlo por los gastos inútilmente realizados para celebrar el contrato confiando en su ejecución, y asimismo en las ganancias que se habría obtenido derivadas de negocios alternativos a los cuales hubiera renunciado". 150

Mientras que el resarcimiento por lesión del interés positivo se da fundamentalmente en el caso de resolución por incumplimiento, el resarcimiento por lesión del interés negativo se da en caso de rescisión. ${ }^{151}$ Esto es importante tener en cuenta pues es lo que permite determinar los conceptos que debe comprender, y aquellos que no, el resarcimiento de daños y perjuicios. Ahora bien, de acuerdo al artículo 1786 del Código Civil el comitente debería pagar a al contratista, lo que este "hubiere podido ganar si

147 RAVERA, Enrico, Op. Cit., p 311. En el mismo sentido, MASCARELLO, Carmela, Op. Cit., p. 206.

148 RAVERA, Enrico, Op. Cit., p 311. En el mismo sentido, MASCARELLO, Carmela, Op. Cit., p. 206.

149 TRIMARCHI, Pietro, Interesse positivo e interesse negativo nella risoluzione del contratto per inadempimento. En: Rivista di Diritto Civile, Anno XLVIII, No. 5, Settembre - Ottobre, CEDAM, Padova, 2002, p. 637.

150 TRIMARCHI, Pietro, Interesse positivo e interesse negativo nella risoluzione del contratto per inadempimento. En: Op. Cit., p. 637.

151 Ver artículo 1370 del Código Civil. Asimismo, es la que se da en el caso de la responsabilidad pre contractual (ver al respecto FRANZONI, Massimo, // danno risarcibile. En: Ob. Cit., p. 91). Respecto al interés negativo ver TURCO, Claudio, Interesse negativo e responsabilità precontrattuale, Giuffrè, Milano, 1990. 
la obra hubiera sido concluida" ¿Quiere decir esto que el comitente debe resarcir al contratista pagando la retribución que le correspondía pagar si el contrato hubiera sido ejecutado hasta su vencimiento? La respuesta es NO. Como señala Franzoni "el interés positivo no se identifica con la contraprestación pactada". 152

El parágrafo 649 del BGB, plantea las cosas de una manera similar:

"El comitente puede, en cualquier momento hasta la terminación de la obra, denunciar el contrato. Sipresenta dicha denuncia, el artífice está facultado a pretender la remuneración acordada; el empresario debe deducir, sin embargo, lo que se ahorra en gastos como consecuencia de la invalidación del contrato, - lo que adquiere u omite maliciosamente adquirir mediante una aplicación ulterior de su capacidad de trabajo".

Si tenemos en cuenta que el resarcimiento es por la lesión del interés positivo lo que supone colocar al contratista en una situación económica equivalente a aquella en la cual se habría encontrado si el contrato hubiese sido exactamente cumplido, entonces no tiene sentido pagar toda la retribución pendiente por cuanto ello supondría colocar al contratista en una mejor situación de la que se hubiera encontrado.

En efecto, el contratista para ejecutar la prestación tendría que haber incurrido en una serie de costos, de tal manera que "lo que hubiere podido ganar sila obra hubiera sido concluida" es la retribución pendiente menos los costos en los que hubiera incurrido. En otras palabras lo que corresponde pagar al comitente es el margen de utilidad del contratista. Como señalan Parisi y Cenini, la parte lesionada "tiene el derecho de percibir la utilidad que habría obtenido del cumplimiento (...) $)^{\prime 153}$ o en palabras de Trimarchi: de "(...) conseguir el valor del negocio, sobre elcual había confiado".154

Veamos un ejemplo numérico:

Si el contrato se hubiese ejecutado.- Por la ejecución de la obra el comitente habría pagado como retribución al contratista 100 .

Los 100, que es la retribución cobrada por el contratista, está estructurada sobre la base de los costos, directos e indirectos, fijos y variables, en los que incurre el contratista para la ejecución de la obra (C) y el margen de utilidad (MU).

Asumamos que el margen de utilidad del contratista es el $10 \%{ }^{155}$, entonces 90 sirve para cubrir los costos incurridos en la ejecución de la obra (C) y 10 es la utilidad (MU) percibida por el contratista.

En otras palabras el contratista habría obtenido una ganancia por la ejecución de la obra de 10.

En los contratos de construcción la determinación de la utilidad será muy sencilla. En efecto, en los presupuestos de obra se establece el costo directo, el costo indirecto y la utilidad del contratista. El primero es la suma de los costos de materiales, mano de obra, equipos, herramientas y todos los elementos requeridos para la ejecución de la obra. El costo directo es el que se puede aplicar a una partida determinada. Los costos indirectos, en cambio, son todos

152 FRANZONI, Massimo, // danno risarcibile. En: Op. Cit., p. 89.

153 PARISI, Francesco y CENINI, Marita, Interesse positivo, interesse negativo e incentivi nella responsabilita contrattuale: un analisi economica e comparata, Rivista di Diritto Civile, Supplemento annuale di studi e ricerche, CEDAM, Padova, 2008, p. 220.

154 TRIMARCHI, Pietro, Interesse positivo e interesse negativo nella risoluzione del contratto per inadempimento. En: Op. Cit., p. 637.

$155 \mathrm{El}$ margen de utilidad es la diferencia entre el precio de venta y el costo del bien o servicio vendido. Generalmente se expresa en porcentaje. Este porcentaje puede calcularse sobre el precio de venta o sobre el valor de costo. 
aquellos que no se pueden aplicar a una partida determinada sino al conjunto de la obra. Se les llama Gastos Generales los cuales se subdividen en: "Gastos Generales no relacionados con el tiempo de ejecución de la obra", por ejemplo, gastos por compra de bases, gastos de visita a la obra, gastos de las garantías que deben presentarse y "Gastos Generales relacionadas con el tiempo de ejecución de la obra", por ejemplo, gastos de administración de la obra, gastos de administración en oficina y gastos financieros relativos a la obra: ${ }^{156}$

Si el contrato no se ejecuta y se resuelve por incumplimiento del comitente.- Si se ordenara que el comitente pague los 100 (como si el contrato se hubiese cumplido normalmente) tendríamos lo siguiente: si al no haberse ejecutado la prestación el contratista no ha incurrido en costos para ejecutarla $(C=0)$, entonces su ganancia (MU) sería de 100 , con lo cual estaría obteniendo un enriquecimiento no justificado y como señala Salvi"(...) el resarcimiento no puede importar el enriquecimiento de la víctima".157

Por tanto, si lo que se busca con el resarcimiento por la lesión del interés positivo es colocar al contratante lesionado en una situación econó- mica equivalente a aquella en la cual se habría encontrado si el contrato hubiese sido exactamente cumplido, entonces la indemnización que corresponde al contratista es, en principio, de 10.

Como señala Mascarello: "La carga de la prueba del daño sufrido incumbe al contratista mientras que el comitente podrá eventualmente deducir la compensatio lucri cum damno y por tanto detraer las ventajas económicas que, por efecto del receso, se hubieran generado a favor del contratista". ${ }^{58}$

La compensatio lucri cum damno es el principio según el cual la determinación del daño resarcible debe tener en cuenta los efectos ventajosos para quien sufre el daño que tienen como causa directa el hecho dañoso. En este caso, la compensación del lucro con el daño solo puede operar cuando el receso sea causa y no simple ocasión de la ventaja.

No se encuentra consagrado en una norma del Código Civil, sin embargo, la doctrina y jurisprudencia italiana la admiten, fundamentalmente en materia de responsabilidad por hecho ilícito. ${ }^{159}$

156 Ver RAMOS SALAZAR, Jesús, Costos y Presupuestos en edificaciones, Décima Edición, CAPECO, Lima, 2008.

157 SALVI, Cesare, La responsabilitá civile, Trattato di Diritto Privato, Giuffrè, Milano, 2005, p. 251.

158 MASCARELLO, Carmela, Op. Cit., p. 206.

159 Ver FRANZONI, Massimo, II danno risarcibile, En: Op. Cit., p. 37 y ss. BIANCA, Massimo, Diritto Civile. 5 La responsabilità, Op. Cit., p. 150. Un ejemplo clásico es el del cazador que con un mismo tiro de escopeta mata a la misma vez a una paloma del vecino y a un halcón que estaba por atrapar una segunda paloma (ver GALLO, Paolo, Arricchimento senza causa. En: /l Codice Civile Commentario, Fondato da Piero Schlesinger, diretto da D. BUSNELLI, Francesco, Giuffrè, Milano, 2003, p. 146). 